\title{
Ocean acidification may slow the pace of tropicalization of temperate fish communities
}

\author{
Ericka Coni ${ }^{1}{ }^{1}$, Ivan Nagelkerken ${ }^{1 凶}{ }^{\circledR}$, Camilo Ferreira', Sean D. Connell ${ }^{1}{ }^{1}$ and David J. Booth ${ }^{2}$
}

\begin{abstract}
Poleward range extensions by warm-adapted sea urchins are switching temperate marine ecosystems from kelp-dominated to barren-dominated systems that favour the establishment of range-extending tropical fishesa. Yet, such tropicalization may be buffered by ocean acidification, which reduces urchin grazing performance and the urchin barrens that tropical range-extending fishes prefer. Using ecosystems experiencing natural warming and acidification, we show that ocean acidification could buffer warming-facilitated tropicalization by reducing urchin populations (by $\mathbf{8 7 \%}$ ) and inhibiting the formation of barrens. This buffering effect of $\mathrm{CO}_{2}$ enrichment was observed at natural $\mathrm{CO}_{2}$ vents that are associated with a shift from a barren-dominated to a turf-dominated state, which we found is less favourable to tropical fishes. Together, these observations suggest that ocean acidification may buffer the tropicalization effect of ocean warming against urchin barren formation via multiple processes (fewer urchins and barrens) and consequently slow the increasing rate of tropicalization of temperate fish communities.
\end{abstract}

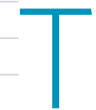
he geographical ranges of species naturally ebb and flow through time ${ }^{1}$. Nonetheless, human-mediated environmental disturbances have intensified and allowed many species to extend their distributions to new environments ${ }^{2}$. The increase in global temperature has forced many warm-adapted species (for example, sea urchins and tropical fishes) to expand their range poleward-a process referred to as tropicalization ${ }^{3,4}$. These changing species distributions can result in altered or novel biological interactions, often triggering modifications to the recipient ecosystem $^{5-7}$, such as the phase shift from the kelp-dominated to barren-dominated stage caused by the poleward extension of the warm-adapted temperate sea urchin Centrostephanus rodgersi $i^{8,9}$. This shift to barren states might facilitate the presence of tropical fishes on temperate reefs (native invasions), which tend to have greater associations with non-macroalgae-forming habitats ${ }^{10}$. Yet, the future ranges of tropical species and the consequent rates of tropicalization in temperate ecosystems remain uncertain because warming is not the only global environmental driver that will alter the structure of ecological communities.

Ocean acidification and global warming are known to directly alter the structure of marine habitats ${ }^{11-13}$ and the resources that species depend on to survive ${ }^{14,15}$. Warming drives loss of kelp forests directly (for example, through heatwaves ${ }^{12}$ ) and indirectly by intensifying herbivory (for example, range extensions of warm-adapted sea urchins $^{3}$ and tropical herbivorous fishes ${ }^{7}$ ). Yet, loss of kelp may also be driven by ocean acidification that triggers the superior competition of algal turfs that benefit from $\mathrm{CO}_{2}{ }^{13,16}$. While habitat-forming organisms such as kelps and seagrasses can benefit directly from increased $\mathrm{CO}_{2}{ }^{17-20}$, shifts towards turf-forming algae are likely to be more common because warming and acidification combine to reduce the performance of habitat-creating species but increase turf performance (for example, in kelp systems s $^{21,22}$ and coral systems $\mathrm{s}^{23,24}$ ). Yet, it is important to highlight that the majority of community-level studies have focused on the single, direct and negative effects of abiotic change, ignoring the fact that ocean acidification and warming can combine in synergistic and antagonistic ways ${ }^{25}$. In some cases, for example, change in one stressor may act as a resource to boost abundances $\left(\mathrm{CO}_{2}\right.$ can enhance algal productivity $^{16}$ or fish abundances ${ }^{14}$ ) or it may act as a stressor to suppress abundances (temperature can negatively affect secondary producers ${ }^{26}$ ).

Tests of the simultaneous effect of ocean acidification and warming are often easier to achieve through laboratory experiments than field experiments ${ }^{27}$. However, the biological outcomes of laboratory experiments may not match those of field experiments ${ }^{28}$ because of the mediating influence of ecological interactions ${ }^{29}$ that buffer change ${ }^{30}$. In addition, almost all experimental studies involve the response of organisms to abrupt changes, ignoring the fact that climate conditions are gradually changing and the rates of the organism responses may differ from abrupt to gradual changes that occur in nature ${ }^{31}$. Although it is not possible to study the gradual effect of ocean acidification at $\mathrm{CO}_{2}$ vents, recently, many studies have highlighted the benefit of natural $\mathrm{CO}_{2}$ vents to evaluate the effect of future $\mathrm{CO}_{2}$ conditions in situ on organisms naturally adapted and exposed long term to reduced $\mathrm{pH}$ levels. Observations from natural systems may therefore complement and even improve laboratory experiment findings because they increase the predictive value of the effects of future climate ${ }^{16,32}$.

There has been considerable focus on how global warming enhances the poleward movement of warm-adapted species ${ }^{33,34}$, but there is almost nothing known on how ocean acidification might accelerate or buffer these range extensions, despite the fact that both stressors will increase in strength in the near future ${ }^{35}$. One key issue for marine systems is the divergent forecasts of ocean warming and ocean acidification on the foraging effects of ecosystem engineers such as warm-adapted sea urchins, particularly the consequences of their range expansion to cooler latitudes. While warming is considered a primary driver of the expansion of their barrens at cooler latitudes by increasing urchin abundances leading to overgrazed kelp forests ${ }^{36}$, ocean acidification might inhibit the creation of barrens by reducing urchin fitness and abundance, allowing an increase of non-calcified organisms. Although some sea urchin species may be able to adapt to ocean acidification ${ }^{37}$, such phase shift may still occur where the $\mathrm{CO}_{2}$-driven boost to primary productivity

'Southern Seas Ecology Laboratories, School of Biological Sciences, The University of Adelaide, Adelaide, South Australia, Australia. ${ }^{2}$ Fish Ecology Lab,

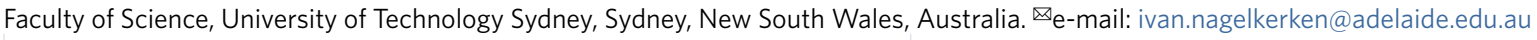




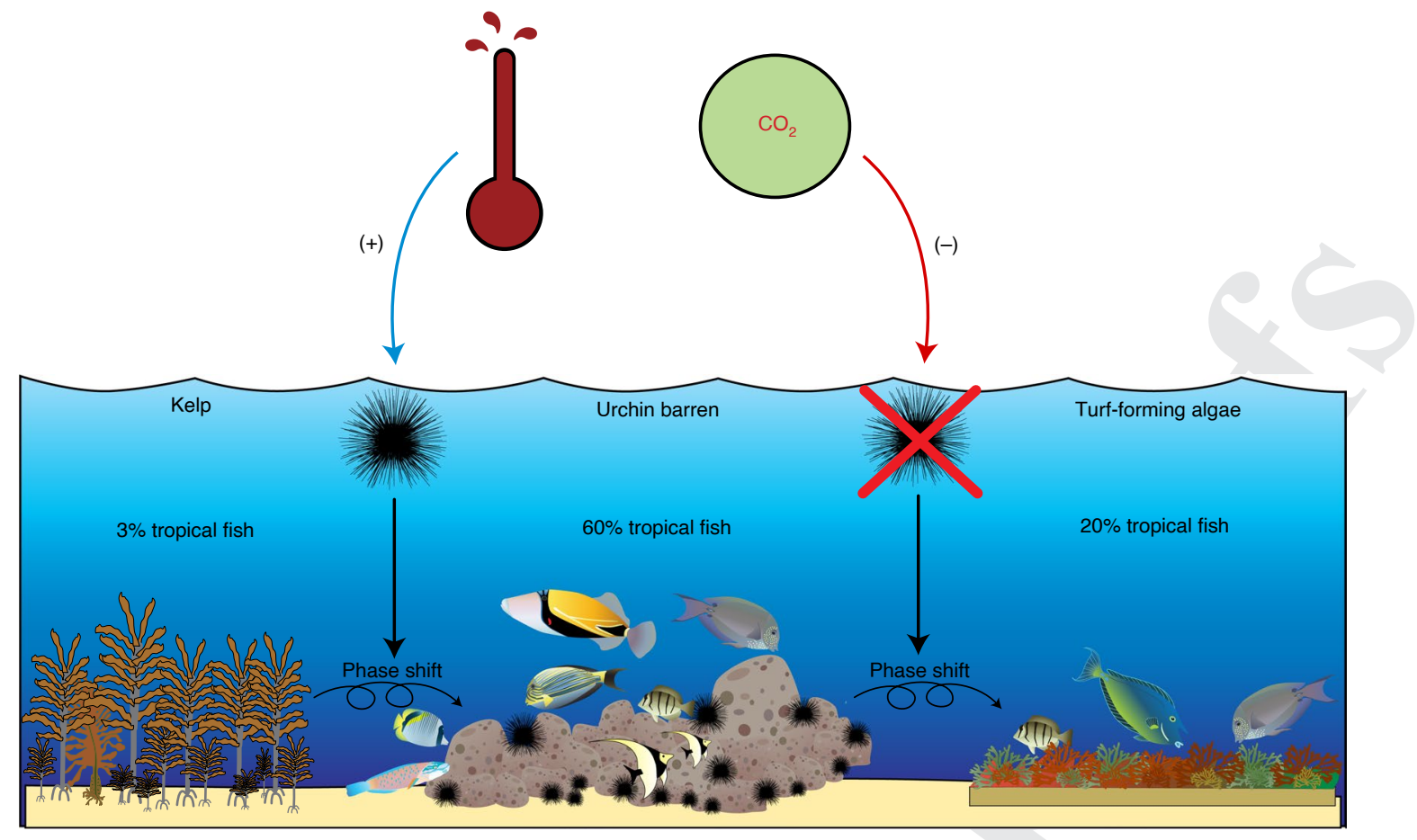

Fig. 1 | Schematic depicting the potential direct, indirect, negative and positive effects of ocean warming and ocean acidification on sea urchin-induced habitat phase shifts and the cascading effects on species richness of range-extending tropical fishes in temperate ecosystems. Elevated temperature enables the range expansion of sea urchins, driving a phase shift from natural kelp forests to rocky barrens. Ocean acidification, however, decreases range-extending urchin densities (via negative physiological effects) and enables a phase shift from barrens to turf-dominated habitats (via $\mathrm{CO}_{2}$ enrichment). Hence, the invasion of tropical fishes in temperate waters may be slowed by ocean acidification. The symbols used are courtesy of the Integration and Application Network, University of Maryland Center for Environmental Science (ian.umces.edu/symbols/). The plus and minus signs represent positive and negative effects. Percentage values represent the relative fish species richness per habitat.

overwhelms the capacity of urchins to compensate through herbivory ${ }^{13}$.

To investigate how these opposing effects might influence the rate of tropicalization, we assessed whether ocean acidification might not only buffer the effects of ocean warming (that is, inhibit urchin barrens) but also mediate the rate of tropicalization (that is, accelerate or inhibit recruitment of tropical fishes). Because it was not possible to investigate these two stressors simultaneously in situ and in an orthogonal way, we present a new approach to this vexing challenge using two different natural laboratories connected by a strong biological link to study ocean warming (tropicalization hotspots ${ }^{38}$ ) and ocean acidification (natural $\mathrm{CO}_{2}$ vents ${ }^{39}$ ), both containing the range-expanding sea urchin (C. rodgersii) as an important habitat engineer. While warming hotspots represent ongoing warming, natural $\mathrm{CO}_{2}$ vents represent $\mathrm{pH}$ conditions forecast for the end of the century (under various Representative Concentration Pathway (RCP) greenhouse gas emission scenarios). Nevertheless, our findings are important to anticipate how the effects of warming on tropicalization (that is, at the leading edges of warm-adapted species distributions where species track their native thermal niches) might be transformed by acidification in the near future.

Here, we first observed whether moderate ocean acidification ( RCP 4.5-6.0) might reduce the densities of sea urchins and the extent of barrens (at $\mathrm{CO}_{2}$ vents), both of which would otherwise increase under ocean warming. We then propose a novel phase shift from barren to turf habitat when the effects of acidification are included (Fig. 1). Finally, we consider how these shifts may also change the rate of establishment of range-extending tropical fishes (that is, we observe whether tropicalization of fishes is facilitated by urchin barrens and turf habitats). Understanding the rate of barren formation and its effect on invading tropical reef fishes has direct implications for understanding the tropicalization of temperate ecosystems in general.

\section{Fish community composition across habitats}

Species richness (Fig. 2a; one-way analysis of variance (ANOVA): $F=28.88 ; P<0.0001$ ), density (Fig. $2 b ; F=18.68 ; P<0.0001)$ and biomass (Fig. 2 c; $F=19.55 ; P<0.0001$ ) of tropical fishes were highest on sea urchin barrens, lowest in kelp forests and intermediate on oyster beds and algal turf. Likewise, native temperate fishes showed the highest species richness (Fig. $2 \mathrm{~d} ; F=14.61 ; P<0.0001$ ), total density (Fig. 2e; $F=11.61 ; P<0.0001$ ) and biomass on sea urchin barrens (Fig. 2f; $F=5.842 ; P<0.001$ ). However, the three other habitats showed similar richness, densities and biomass. At the $\mathrm{CO}_{2}$ vents, native temperate fish species richness, total density and biomass were not significantly different among habitats (Fig. $2 \mathrm{~g}-\mathrm{i}$ ), except for a higher biomass at the vent with highest $\mathrm{PCO}_{2}$ values (Supplementary Fig. 1).

The fish community composition differed significantly among habitats for tropical (Supplementary Fig. 2; analysis of similarities (ANOSIM): global $R=0.36 ; P=0.0002$ ) and native temperate (Supplementary Fig. 2; global $R=0.29 ; P=0.0002$ ) fishes in south-eastern Australia, and for local species at $\mathrm{CO}_{2}$ vents in New Zealand (Supplementary Fig. 2; global $R=0.06 ; P=0.042$ ). For both tropical and temperate fish assemblages, pairwise tests revealed that all habitats significantly differed from each other in Australia, while for the fish community at the $\mathrm{CO}_{2}$ vents, kelp forests were the most dissimilar habitat (Supplementary Table 3a). The tropical fishes that contributed most to the dissimilarities among habitats were the common species sergeant major Abudefduf vaigiensis (most abundant on oyster and urchin barren habitats) and dusky surgeonfish Acanthurus nigrofuscus (most abundant on urchin barrens), contributing to 
a
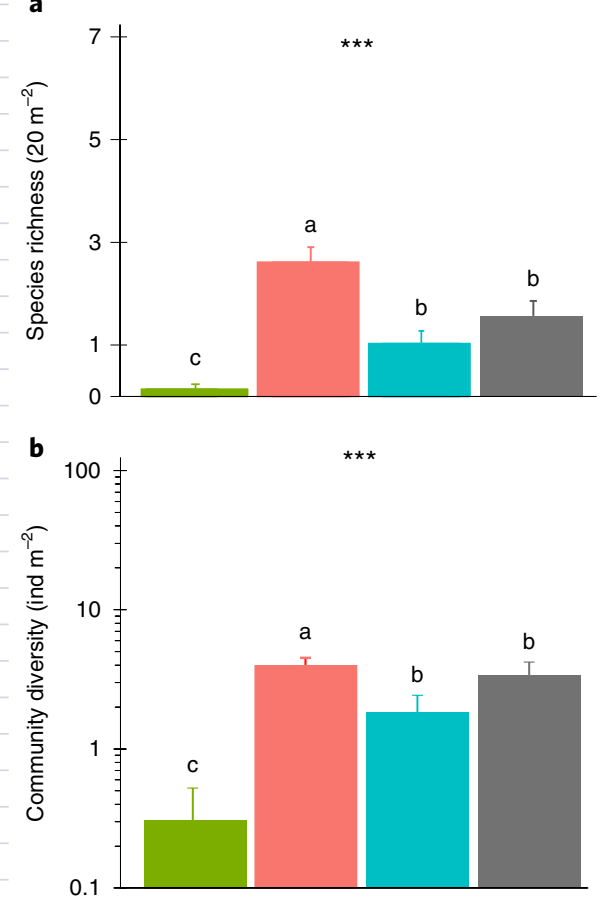

c

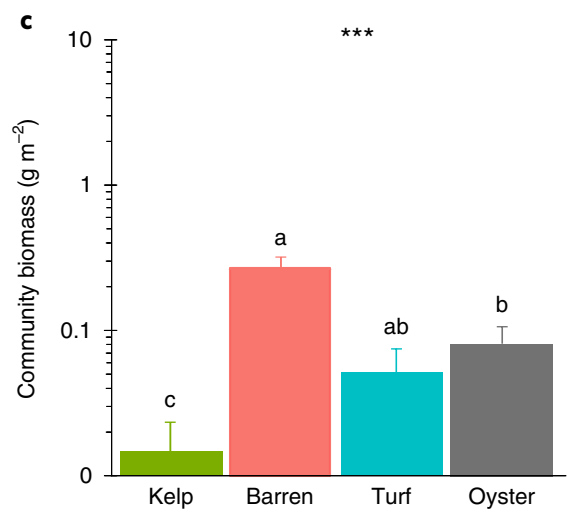

d

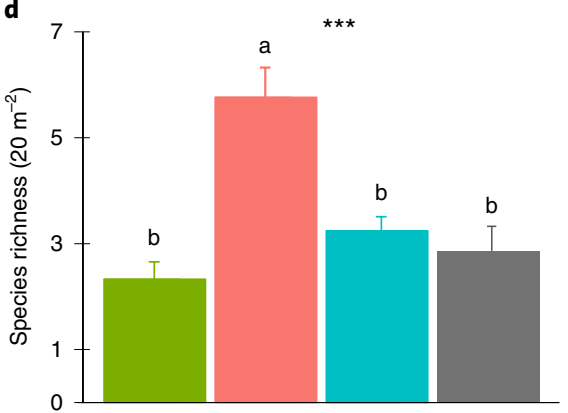

e

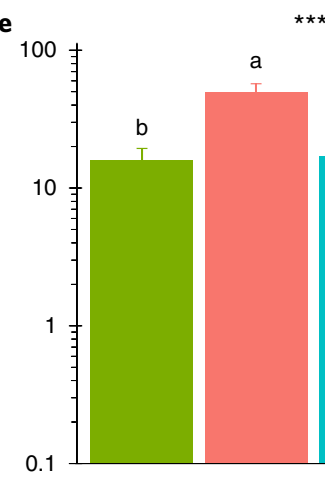

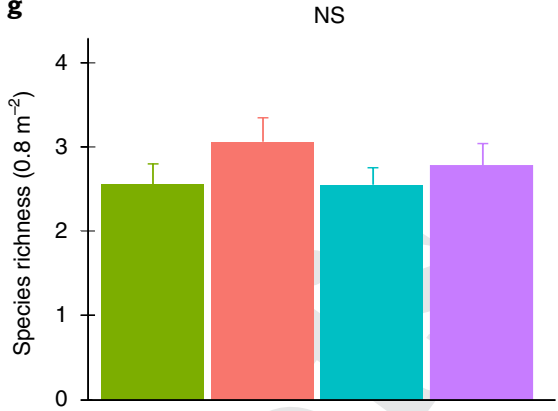

f

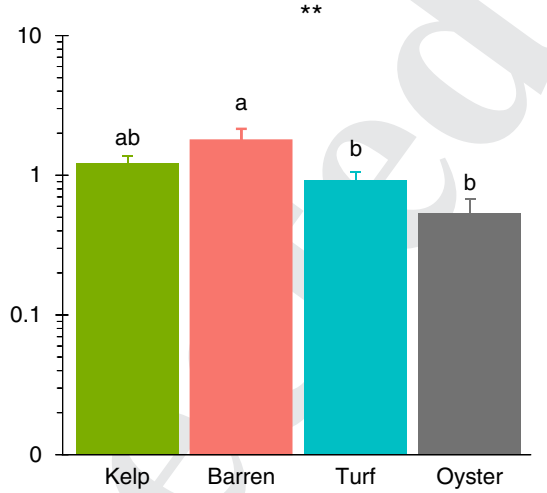

h

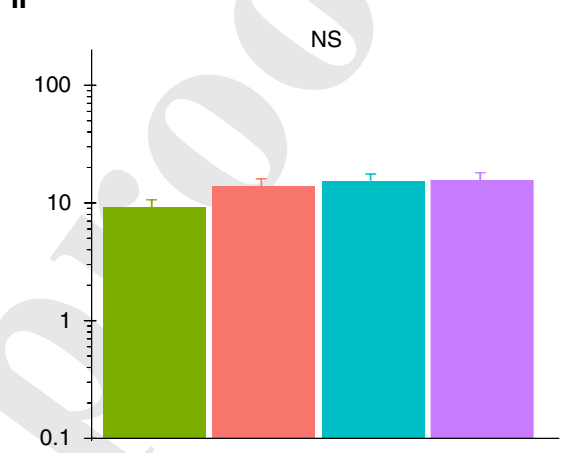

i

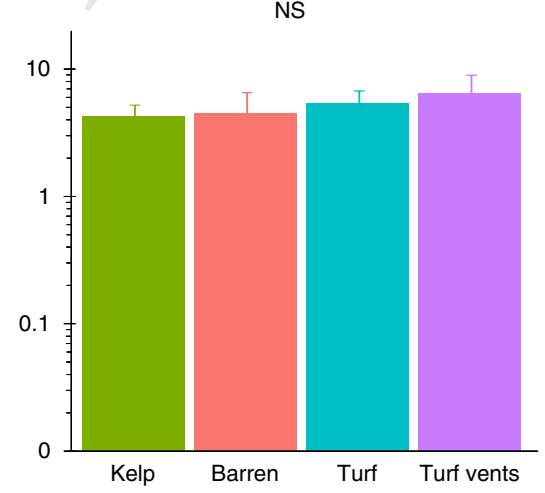

Fig. 2 | Structure of fish assemblages across different coastal habitats, showing urchin barrens as a key habitat for tropical and temperate fish assemblages while kelp habitat is avoided by tropical fishes. $\mathbf{a}-\mathbf{i}$, Species richness per transect ( $\mathbf{a}, \mathbf{d}$ and $\mathbf{g})$, density (b,e and $\mathbf{h})$ and biomass (c, $\mathbf{f}$ and i) for range-extending tropical fish communities of south-eastern Australia (a-c), local temperate fish communities of south-eastern Australia (d-f) and temperate fish communities at $\mathrm{CO}_{2}$ vents (turf vents) and three control habitats at White Island, New Zealand. The data represent means and standard error. Statistical significance was determined by ANOVA $\left.{ }^{\star \star} P<0.01 ;{ }^{\star \star \star} P<0.001\right)$. NS, not significant. Different letters above the bars indicate significant

[07 differences among habitats (as determined by post-hoc tests). At the vents, the benthic cover was dominated by turf algae; therefore, it was considered as [8 $\mathbf{0 g}$ the only vent habitat. The $y$ axes in $\mathbf{b}, \mathbf{c}, \mathbf{e}, \mathbf{f}, \mathbf{h}$ and $\mathbf{i}$ have been log-scaled for consistency."

approximately half of the dissimilarities (Supplementary Table 4). For the temperate fish community, mado Atypichthys strigatus (kelp forests) and hulafish Trachinops taeniatus (urchin barrens) together were responsible for $\sim 41-60 \%$ of the dissimilarity among habitats (Supplementary Table 5). Finally, at the $\mathrm{CO}_{2}$ vents community, 56$66 \%$ of the dissimilarity among habitats was attributed to the common triplefin (Forsterygion lapillum) (Supplementary Table 6).

Functional composition of fish communities across habitats The trophic functional composition of the tropical fish community (Supplementary Table 3b; ANOSIM: global $R=0.28 ; P=0.0002$ ) clearly differed among the four habitats in Australia, except for turf and oyster habitats. For the temperate fish community, however, barrens comprised the only habitat that significantly differed from the other habitats (Supplementary Table 3b; global $R=0.25 ; P=0.0002$ ). Most of the functional groups of tropical fishes were associated with barrens, except for planktivores, which were also highly associated with oyster reefs (Fig. 3 and Supplementary Table 7). For the temperate fish species in Australia, roving grazing herbivores, territorial grazing herbivores, both browsing and grazing herbivores, and planktivores were most associated with barrens, and they were the functional groups that overlapped in habitat use for tropical and temperate fish assemblages (Fig. 3 and Supplementary Table 7). Only temperate functional groups (particularly omnivores, kelp feeders, browsing herbivores and herbivorous detritivores) were associated with kelp habitats. Turf and oyster-dominated habitats were associated with few functional groups: temperate invertivores and temperate carnivores, respectively.

\section{Response of sea urchin populations to elevated $\mathrm{CO}_{2}$}

Both the temperate native (Supplementary Fig. 3; one-way ANOVA: $P=0.001$ ) and warm-adapted (Supplementary Fig. 3; one-way 

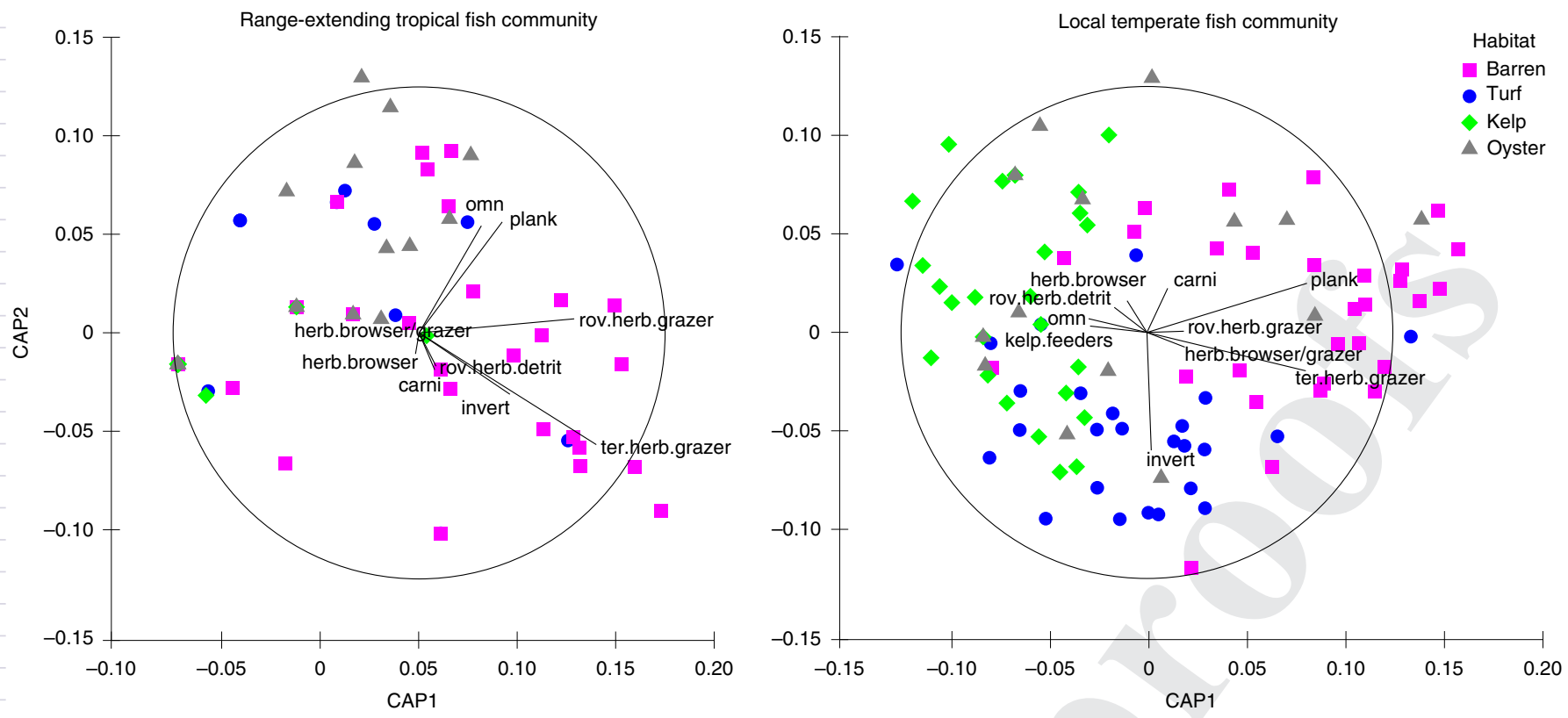

Fig. 3 | CAP ordination based on Bray-Curtis distance, showing the correlation between trophic functional groups of range-extending tropical and local temperate fish assemblages, respectively, with temperate reef habitats of south-eastern Australia. The vectors (black lines) show the correlation of each functional group with each habitat and their lengths indicate the magnitude of this correlation. carni, carnivores; herb.browser, browsing herbivores; herb. browser/grazer, browsing and grazing herbivores; invert, invertivores; kelp.feeders, kelp feeders; omn, omnivores; plank, planktivores; rov.herb.detrit, roving herbivorous detritivores; rov.herb.grazer, roving grazing herbivores; ter.herb.grazer, territorial grazing herbivores.

ANOVA: $P=0.021$ ) sea urchins occurred in greater density at control sites compared with elevated $\mathrm{CO}_{2}$ vent sites. Although the low $R^{2}$ indicates high unexplained variability by the regression line (probably caused by the higher number of zeros, especially for the warm-adapted sea urchins), densities of both sea urchin species still showed a significant decline with reduced $\mathrm{pH}$ (Fig. 4a,b; linear regression for native sea urchins: $R^{2}=0.22 ; P=0.0001$; linear regression for warm-adapted sea urchins: $\left.R^{2}=0.08 ; P=0.019\right)$. The warm-adapted sea urchins showed higher sensitivity than the native species to reduced $\mathrm{pH}$, with densities at $\mathrm{pH}<8.0$ being zero, and they were only observed at $\mathrm{pH}$ levels ranging between 8.09 and 8.30. Native urchins were found down to $\mathrm{pH}$ levels of 7.2, albeit at very low densities.

Heavy metal, trace element and sulfur concentrations in seawater sampled at the study sites did not differ between controls and vents across years (Supplementary Table 2). Therefore, these abiotic factors are deemed unrelated to altered sea urchin densities and barren sizes between controls and vents. Only $\mathrm{pH}$ and $\mathrm{p}_{\mathrm{CO}_{2}}$ differed significantly between vents and controls.

At the control sites in New Zealand, barren size was positively related to sea urchin density (Fig. 4c; both species combined: $R^{2}=0.86 ; P=0.0001$ ) and $\mathrm{pH}$ (Fig. $4 \mathrm{~d} ; R^{2}=0.37 ; P=0.036$ ) but not to urchin body size (Supplementary Fig. 4; both species combined: $\left.R^{2}=0.30 ; P=0.101\right)$. Native urchin species were significantly larger at vents and barrens than at kelp and turf habitats (Supplementary Fig. 5; one-way ANOVA: $P=0.0001$ ), while body size of the warm-adapted urchin species did not differ among habitats (one-way ANOVA; $P=0.461$ ).

These results show that ocean acidification may buffer the negative effects of ocean warming by inhibiting range-extending urchins so that their abundances are sparser than those required to form barren-dominated habitats in temperate ecosystems. Therefore, these two divergent global forces have opposing effects on the rate of tropicalization. Ocean warming facilitates the range expansion and recruitment of tropical vagrant fishes by mediating a phase shift (through urchins) from a kelp-dominated to a barren-dominated state (resulting in a 20 -fold increase in densities and biomass and a 3.5-fold increase in species richness of tropical vagrant fishes at their leading edges). Ocean acidification acts as a stressor on urchins so that their sparser densities are insufficient to form barrens, but also facilitates the emergence of turf-dominated habitats that are directly boosted by $\mathrm{CO}_{2}$ nutrient enrichment. The individual effect of elevated $\mathrm{CO}_{2}$ on reduced sea urchin density and barrens and the regimen shift towards turf-dominated habitats have also been observed at other natural $\mathrm{CO}_{2}$ vents ${ }^{40-42}$. Considering the sole effect of urchin overgrazing, a reversal from barrens to kelp habitat is unlikely to occur due to a hysteresis effect in which the pathway of ecosystem recovery differs from the pathway of degradation ${ }^{43}$ (Extended Data Fig. 1). This hysteresis appears strong under a future climate in which physiological performance and abundance of urchins appear reduced by ocean $\mathrm{pH}$ so that shallow temperate ecosystems are less likely to return to their previous natural state of kelp domination. Where warming, acidification and urchin grazing combine, a switch from kelp to turf-dominated habitats would reduce the recruitment of tropical fishes and consequently retard the rate of tropicalization of temperate fish assemblages (see schematic in Fig. 1 and Extended Data Fig. 1). Yet, current models about warming alone suggest accelerated tropicalization as urchin barrens expand in distribution and extent.

The acidification effects we present suggest that the strength of future tropicalization is still unknown. Many tropical fishes are extending their ranges to higher latitudes under warming to stay within their preferred thermal niche ${ }^{44}$. While at their leading edges these species can escape the detrimental effects of warming, they are less likely to escape the effects of increasing $\mathrm{CO}_{2}$ concentrations through range extensions. By studying $\mathrm{CO}_{2}$ vents, we can disentangle the effects that future acidification might have on the establishment of tropical species at the leading edges of their distribution. The mechanisms we reveal for each of these stressors in natural environments appear to have strong potential to interact antagonistically and create very different future ecosystems compared with when they are considered alone. 

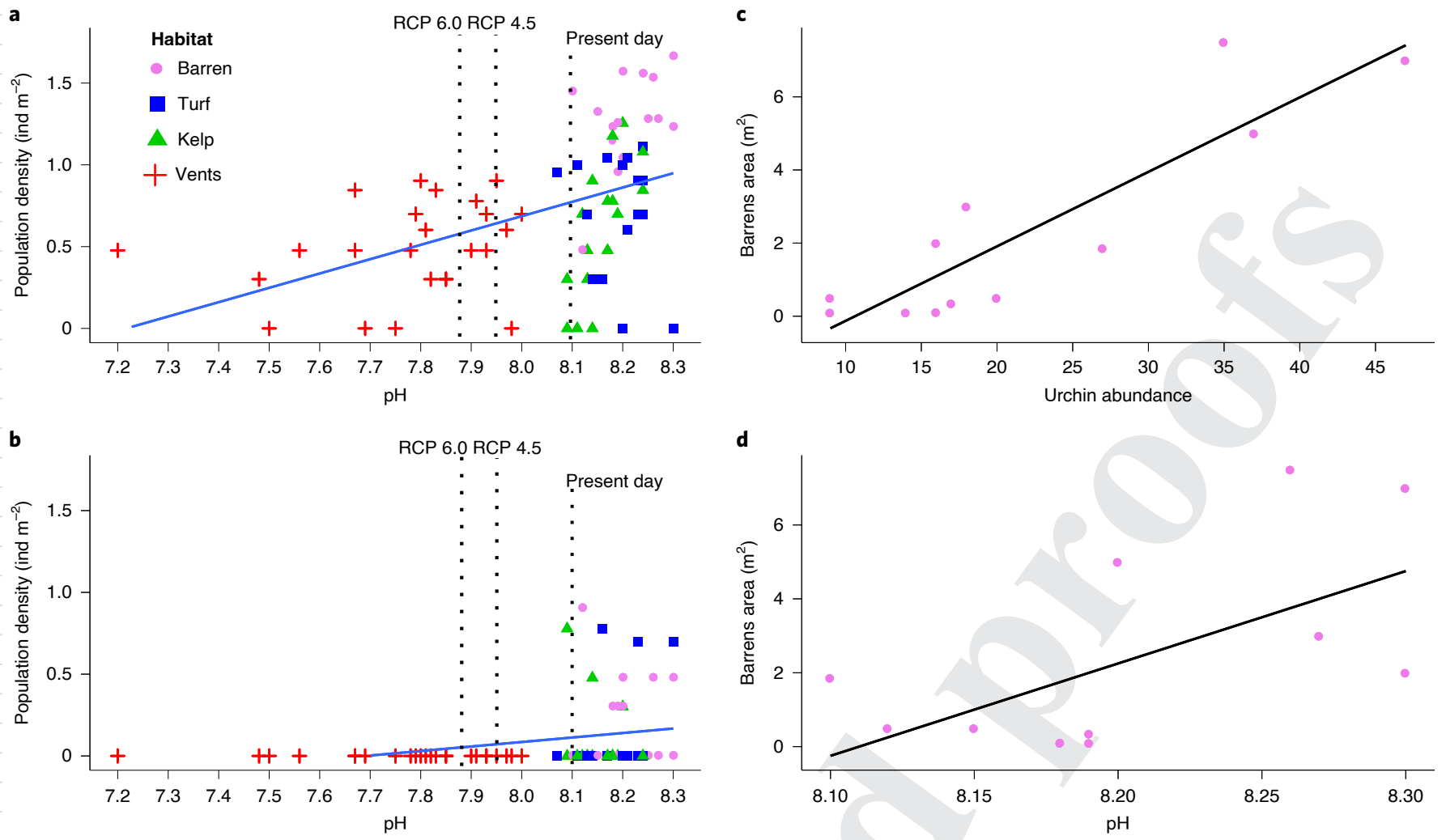

Fig. 4 | Linear regressions showing the relationships between seawater $\mathbf{p H}$, sea urchin density and barren size. $\mathbf{a}, \mathbf{b}$, Density of native temperate sea urchins (E. chloroticus; $\left.R^{2}=0.22 ; P=0.0001\right)$ (a) and warm-adapted sea urchins (C. rodgersii; $\left.R^{2}=0.08 ; P=0.019\right)(\mathbf{b})$ across a $\mathrm{pH}$ gradient at $\mathrm{CO}_{2}$ vents and control habitats (New Zealand). c, Relationship between barren size and total sea urchin abundance $\left(R^{2}=0.86 ; P=0.0001\right)$. d, Relationship between sea urchin barren size and $\mathrm{pH}\left(R^{2}=0.37 ; P=0.036\right)$. Sea urchin density data on the yaxes of $\mathbf{a}$ and $\mathbf{b}$ were $\log _{10}[x+1]$ transformed. Vertical dashed lines indicate the global average of present-day and future seawater $\mathrm{pH}$ for the twenty-first century according to RCP scenarios by Bopp et al. ${ }^{35}$.

Our findings suggest that, in temperate systems, urchin barrens sustain the highest biomass and a more diverse and abundant tropical fish community than structurally more complex habitats. As such, barrens are a key habitat for tropical fish to establish viable populations on temperate reefs. These findings are consistent with previous observations showing that most tropical species prefer non-macroalgal rocky habitats ${ }^{10}$. Urchin barrens are hard substrata usually covered only with a thin layer of filamentous algae, which is a principal food source for grazing herbivores and, for example, explains why the tropical herbivorous dusky surgeonfish A. nigrofuscus was strongly associated with this habitat ${ }^{45,46}$. Although the most abundant tropical species $A$. vaigiensis was relatively more abundant in oyster-dominated habitats, it also had high abundances in urchin barren-dominated habitats, which may be explained by the fact that: (1) A. vaigiensis usually forages in the water column and in areas with intense water movement, which may coincide with the same areas where oyster reefs and urchin barrens are found; and (2) oysters and urchins also create hard-substrate habitats that provide refuge for many temperate and tropical fishes that prefer habitats free from algae ${ }^{47-49}$. As such, declines in oyster reefs mediated by climate change $e^{50,51}$ and overfishing in Australia ${ }^{52}$ may further reduce the establishment of the most common vagrant tropical fish in temperate ecosystems.

Various temperate fish species (24\% of total temperate species) were observed inhabiting and/or foraging in kelp-dominated habitats, suggesting that kelp forests are a key habitat for the maintenance of temperate reef fish diversity and their population abundances. Besides overgrazing by urchins, additional collapse of kelp forests driven by climatic disturbances (for example, marine heatwaves, ocean acidification and range extensions of tropical herbivorous fishes ${ }^{7,12,13}$ ) may further disrupt the structure of temperate fish communities by opening up more suitable habitat for range-extending coral reef fishes. Temperate fishes were similarly associated with turf and kelp-dominated habitats. In contrast, vagrant tropical fishes almost completely avoided kelp habitats while some species were associated with turf habitats. This suggests that: (1) although tropical fishes are highly associated with barrens (due to increasing warming), a regimen shift to turf-dominated habitats (with increasing $\mathrm{CO}_{2}$ ) will not completely inhibit the establishment of tropical fishes in temperate ecosystems and will only slow the pace of tropicalization; and (2) a regimen shift from present-day kelp domination to turf-dominated systems (with increasing warming and acidification combined ${ }^{12,53,54}$ ) is more likely to have a greater positive effect on vagrant tropical fishes than resident temperate fishes, facilitating the creation of novel community structures under future climate.

The tropical and temperate trophic functional group that overlapped most in habitat use (on urchin barrens) was the grazing herbivorous fishes. The increasing density of grazing herbivorous fishes on temperate reefs may intensify the grazing pressure on kelp forests, hindering their capacity to recover once they have turned into barrens $s^{7,55}$. Alternatively, such overlap in habitat use is expected to increase niche competition, which can lead to niche displacement depending on which species has a higher competitive ability ${ }^{56}$. To a lesser extent, planktivores also overlapped in habitat use. However, unlike grazing herbivores, tropical and temperate planktivores are usually observed schooling together, allowing tropical species to increase their survivorship in temperate environments ${ }^{57}$. Thus, by adopting this social behaviour, tropical and temperate planktivo- 
rous fishes might share the same habitat and coexist in temperate ecosystems under climate change ${ }^{58,59}$.

While some laboratory studies have found that sea urchins might adapt to long-term exposure of ocean acidification ${ }^{60,61}$, species living at natural $\mathrm{CO}_{2}$ vents showed little evidence of adaptation potential to ocean acidification ${ }^{62}$. We showed declines in the density of both native and warm-adapted temperate sea urchins and in the size of their barrens in natural ecosystems subjected to long-term elevated $\mathrm{CO}_{2}$. Our results suggest that the reduction in sea urchin densities and the decrease in urchin feeding rates under elevated $\mathrm{CO}_{2}{ }^{13}$ may suppress the formation of urchin barrens under future ocean acidification, as anticipated for species with a reduced scope for adaptation.

Although the effects of ocean acidification on sea urchins vary with species identity ${ }^{63}$ and laboratory design, experimental field and laboratory experiments suggest that our findings might be quite general since sea urchins tend to be considered particularly vulnerable to lowered $\mathrm{pH}$, as observed through reduced performance (for example, grazing rates, growth and reproduction) and reduced density $^{13,64,65}$. This is probably due to a limited extracellular acid-base regulatory ability (that is, homeostatic regulation of the $\mathrm{pH}$ of the body's extracellular fluid), especially when exposed long term ${ }^{66,67}$. Indeed, reciprocal experiments conducted at the same vents where the present study was performed (New Zealand) showed that the feeding rates and densities of the native urchins (Evechinus chloroticus) declined when they were translocated from control to elevated $\mathrm{CO}_{2}$ conditions at vents ${ }^{13}$.

We did not find a relationship between urchin body size and barren formation, probably because of the low sample sizes or the low abundances of $C$. rodgersii, which is considered to be the main sea urchin species that can enable alternative states of shallow reef communities in Australasia ${ }^{36}$. The increase in algal production at elevated $\mathrm{CO}_{2}$ levels provides more food at vents, which might explain the larger-sized native sea urchins at the vents compared with other habitats in temperate (this study) as well as tropical regions ${ }^{68}$. Thus, future $\mathrm{CO}_{2}$ conditions and the decreasing densities and rates of urchin herbivory, combined with ocean warming, might accelerate the expansion of turf algae cover ${ }^{54}$. In contrast, other habitats that are sensitive to one (or a combination) of these stressors, such as barrens (this study) and kelp ${ }^{69,70}$, might be rapidly overgrown by turf-forming algae, which will reduce the density and diversity of range-extending tropical fishes, modifying the trajectory of tropicalization of temperate systems. Despite transgenerational acclimatization to reduced $\mathrm{pH}$ having been observed in the laboratory for some sea urchins ${ }^{71-73}$, the boosted productivity of turfs by $\mathrm{CO}_{2}$ enrichment increases the probability of turf domination where urchin grazing rates are unable to compensate ${ }^{74}$.

The limited evidence for transgenerational adaptation to climate change in fish has shown mixed outcomes and is likely to be species specific $^{75}$. While some studies have found evidence of physiological (growth ${ }^{76}$ ) and behavioural (antipredator behaviour ${ }^{77}$ ) acclimatization through phenotypic plasticity and adaptation, others found little evidence of potential adaptation of fish behaviour to elevated temperature and $\mathrm{CO}_{2}{ }^{78,79}$. The eutrophication effect of elevated $\mathrm{CO}_{2}$ will prompt habitat modifications through the promotion of turf algae expansion in temperate systems and its effects are unlikely to be altered under longer-term exposure. Transgenerational alteration of tropical fish habitat choice in novel temperate habitat composition (turf-dominated habitat) is therefore unlikely to occur.

While ocean warming facilitates tropicalization by creating barren-dominated states, acidification inhibits formation of the preferred barren habitat of tropical fish that is created by urchins. We conclude that the pace of ongoing tropicalization due to climate change may be slowed by ocean acidification through its indirect (inhibiting sea urchin abundances) and direct effects (promoting the expansion of non-barren habitats).

\section{Online content}

Any methods, additional references, Nature Research reporting summaries, source data, extended data, supplementary information, acknowledgements, peer review information; details of author contributions and competing interests; and statements of data and code availability are available at https://doi.org/10.1038/ s41558-020-00980-w.

\section{Received: 20 May 2019; Accepted: 7 December 2020;}

\section{References}

1. Parmesan, C. Ecological and evolutionary responses to recent climate change. Annu. Rev. Ecol. Evol. Syst. 37, 637-669 (2006).

2. Pecl, G. T. et al. Biodiversity redistribution under climate: impacts on ecosystems and human well-being. Science 355, eaai9214 (2017).

3. Ling, S. D. Range expansion of a habitat-modifying species leads to loss of taxonomic diversity: a new and impoverished reef state. Oecologia 156, 883-894 (2008).

4. Feary, D. A. et al. Latitudinal shift in coral reef fishes: why some species do other do not shift. Fish. Fish. (Oxf.) 15, 593-615 (2013).

5. Nakamura, Y., Feary, D. A., Kanda, M. \& Yamaoka, K. Tropical fishes dominate temperate reef fish communities within western Japan. PLoS ONE 8, e81107 (2013).

6. Peers, M. J. L., Wehtje, M., Thornton, D. H. \& Murray, D. L. Prey switching as a means of enhancing persistence in predators at the trailing southern edge. Glob. Change Biol. 20, 1126-1135 (2014).

7. Verges, A. et al. Long-term empirical evidence of ocean warming leading to tropicalization of fish communities, increased herbivory, and loss of kelp. Proc. Natl Acad. Sci. USA 113, 13791-13796 (2016).

8. Ling, S. D., Johnson, C. R., Ridgway, K., Hobday, A. J. \& Haddo, M. Climatedriven range extension of a sea urchin: inferring future trends by analysis of recent population dynamics. Glob. Change Biol. 15, 719-731 (2009).

9. Johnson, C. R., Ling, S. D., Ross, J., Shepherd, S. \& Miller, K. Establishment of the Long-Spined Sea Urchin (Centrostephanus rodgersii) in Tasmania: First Assessment of Potential Threats to Fisheries. FRDC Final Report, Project No. 2001/044 (School of Zoology \& Tasmanian Aquaculture and Fisheries Institute, University of Tasmania, 2005).

10. Beck, H. J., Feary, D. A., Nakamura, Y. \& Booth, D. J. Temperate macroalgae impacts tropical fish recruitment at forefront of range expansion. Coral Reefs 36, 639-651 (2017).

11. Nagelkerken, I. \& Connell, S. D. Global alteration of ocean ecosystem functioning due to increasing human $\mathrm{CO}_{2}$ emissions. Proc. Natl Acad. Sci. USA 112, 13272-13277 (2015).

12. Wernberg, T. et al. Climate-driven regime shift of a temperate marine ecosystem. Science 353, 169-172 (2016).

13. Connell, S. D. et al. The duality of ocean acidification as a resource and a stressor. Ecology 99, 1005-1010 (2018).

14. Nagelkerken, I., Goldenberg, S. U., Ferreira, C. M., Russell, B. D. \& Connell, S. D. Species interactions drive fish biodiversity loss in a high- $\mathrm{CO}_{2}$ world. Curr. Biol. 27, 2177-2184 (2017).

15. Sunday, J. M. et al. Ocean acidification can mediate biodiversity shifts by changing biogenic habitat. Nat. Clim. Change 7, 81-85 (2017).

16. Connell, S. D., Kroeker, K. J., Fabricius, K. E., Kline, D. I. \& Russell, B. D. The other ocean acidification problem: $\mathrm{CO}_{2}$ as a resource among competitors for ecosystem dominance. Proc. R. Soc. B 368, 20120442 (2013).

17. Russell, B. D. et al. Future seagrass beds: can increased productivity lead to increased carbon storage? Mar. Pollut. Bull. 73, 463-469 (2013).

18. Palacios, S. L. \& Zimmerman, R. C. Response of ellgrass Zostera marina to $\mathrm{CO}_{2}$ enrichment: possible impacts of climate change and potential for remediation of coastal habitats. Mar. Ecol. Prog. Ser. 344, 1-13 (2007).

19. Hepburn, C. D. et al. Diversity of carbon use strategies in a kelp forest community: implications for a high $\mathrm{CO}_{2}$ ocean. Glob. Change Biol. 17, 2488-2497 (2011).

20. Linares, C. et al. Persistent natural acidification drives major distribution shifts in marine benthic ecosystems. Proc. R. Soc. B Biol. Sci. 282, 20150587 (2015).

21. Russell, B. D., Thompson, J. A. I., Falkenberg, L. J. \& Connell, S. D. Synergistic effects of climate change and local stressors: $\mathrm{CO}_{2}$ and nutrient-driven change in subtidal rocky habitats. Glob. Change Biol. 15, 2153-2162 (2009)

22. Connell, S. D. \& Russell, B. D. The direct effects of increasing $\mathrm{CO}_{2}$ and temperature on non-calcifying organisms: increasing the potential for phase shifts in kelp forests. Proc. R. Soc. B Biol. Sci. 277, 1409-1415 (2010).

23. Diaz-Pulido, G., Gouezo, M., Tilbrook, B., Dove, S. \& Anthony, K. R. N. High $\mathrm{CO}_{2}$ enhances the competitive strength of seaweeds over corals. Ecol. Lett. 14, 156-162 (2011). 
24. Johnson, M. D., Comeau, S., Lantz, C. A. \& Smith, J. E. Complex and interactive effects of ocean acidification and temperature on epilithic and endolithic coral-reef turf algal assemblages. Coral Reefs 36, 1059-1070 (2017).

25. Kroeker, K. J., Kordas, R. L. \& Harley, D. G. Embracing interactions in ocean acidification research: confronting multiple stressor scenarios and context dependence. Biol. Lett. 13, 20160802 (2017).

26. Goldenberg, S. U., Nagelkerken, I., Ferreira, C. M., Ullah, H. \& Connell, S D. Boosted food web productivity through ocean acidification collapses under warming. Glob. Change Biol. 23, 4177-4184 (2017).

27. Wernberg, T., Smale, D. A. \& Thomsen, M. S. A decade of climate change experiments on marine organisms: procedures, patterns and problems. Glob. Change Biol. 18, 1491-1498 (2012).

28. Kroeker, K. J., Micheli, F., Gambi, M. C. \& Martz, T. R. Divergent ecosystem responses within a benthic marine community to ocean acidification. Proc. Natl Acad. Sci. USA 108, 14515-14520 (2011)

29. Goldenberg, S. U. et al. Ecological complexity buffers the impacts of future climate on marine consumers. Nat. Clim. Change 8, 229-233 (2018).

30. Connell, S. D. \& Ghedini, G. Resisting regime-shifts: the stabilising effect of compensatory processes. Trends Ecol. Evol. 30, 513-515 (2015).

31. Widdicombe, S., Dupont, S. \& Thorndyke, M. Laboratory Experiments and Benthic Mesocosm Studies. Guide for Best Practices in Ocean Acidification Research and Data Reporting (EPOCA, 2008).

32. Hofmann, G. E. et al. High-frequency dynamics of ocean $\mathrm{pH}$ : a multi-ecosystem comparison. PLoS ONE 6, e28983 (2011).

33. Parmesan, C. \& Yohe, G. A globally coherent fingerprint of climate change impacts across natural systems. Nature 421, 37-42 (2003).

34. Hoegh-Guldberg, O. \& Bruno, J. F. The impact of climate change on the world's marine ecosystems. Science 328, 1523-1528 (2010).

35. Bopp, L. et al. Multiple stressors of ocean ecosystems in the 21st century: projections with CMIP5 models. Biogeosciences 10, 6225-6245 (2013).

36. Ling, S. D. et al. Global regime shift dynamics of catastrophic sea urchin overgrazing. Phil. Trans. R. Soc. B 370, 20130269 (2015).

37. Calosi, P. et al. Distribution of sea urchins living near shallow water $\mathrm{CO}_{2}$ vents is dependent upon species acid-base and ion-regulatory abilities. Mar. Pollut. Bull. 73, 470-484 (2013).

38. Booth, D. J., Figueira, W. F., Gregson, M. A., Brown, L. \& Beretta, G. Occurrence of tropical fishes in temperate southeastern Australia: role of the East Australian Current. Estuar. Coast. Shelf Sci. 72, 102-114 (2007).

39. Nagelkerken, I., Russell, B. D., Gillanders, B. M. \& Connell, S. D. Ocean acidification alters fish populations indirectly through habitat modification. Nat. Clim. Change 6, 89-93 (2016).

40. Hall-Spencer, J. et al. Volcanic carbon dioxide vents show ecosystem effects of ocean acidification. Nature 454, 96-99 (2008).

41. Kroeker, K., Gambi, M. C. \& Micheli, F. Community dynamics and ecosystem simplification in a high- $\mathrm{CO}_{2}$ ocean. Proc. Natl Acad. Sci. USA 110, 12721-12726 (2013).

42. Enochs, I. C. et al. Shift from coral to macroalgae dominance on volcanically acidified reef. Nat. Clim. Change 5, 1083-1088 (2015)

43. Suding, K. N. \& Hobbs, R. J. Threshold models in restoration and conservation: a developing framework. Trends Ecol. Evol. 24, 271-279 (2009).

44. Perry, A. L., Low, O. L., Ellis, J. R. \& Reynolds, J. D. Climate change and distribution shifts in marine fishes. Science 308, 1912-1915 (2005).

45. Steneck, R. S. Herbivory on coral reefs: a synthesis. In Proc. 6th International Coral Reef Symposium. Vol. 1, 37-49 (1988).

46. Purcell, S. W. \& Bellwood, D. R. A functional analysis of food procurement in two surgeonfish species, Acanthurus nigrofuscus and Ctenochaetus striatus (Acanthuridae). Environ. Biol. Fishes 37, 139-159 (1993).

47. Curley, B. G., Gillanders, B. M. \& Kingsford, M. J. Spatial and habitat related patterns of temperate reef fish assemblages: implications for the design of marine protected areas. Mar. Freshw. Res. 53, 1197-1210 (2002).

48. Coen, L. D., Luckenbach, M. W. \& Breitburg, D. L. The role of oyster reef as essential fish habitat: a review of current knowledge and some new perspectives. Am. Fish. Soc. Symp. 22, 438-454 (1999).

49. Lenihan, H. S. et al. Cascading of habitat degradation: oyster reefs invaded by refugee fishes escaping stress. Ecol. Appl. 11, 764-782 (2001).

50. Jackson, J. B. C. et al. Historical overfishing and the recent collapse of coastal ecosystems. Science 293, 629-637 (2001).

51. Thomas, Y., Cassou, C., Gernez, P. \& Pouvreau, S. Oysters as sentinels of climatic variability and climatic change in coastal ecosystems. Environ. Res. Lett. 13, 104009 (2018).

52. Alleway, H. K. \& Connell, S. D. Loss of an ecological baseline through the eradication of oyster reefs from coastal ecosystems and human memory. Conserv. Biol. 29, 795-804 (2015).

53. Filbee-Dexter, K. \& Wernberg, T. Rise of turfs: a new battlefront for globally declining kelp forests. BioScience 168, 64-76 (2018).

54. O'Brien, J. M. \& Scheibling, R. E. Turf wars: competition between foundation and turf-forming species on temperate and tropical reefs and its role in regime shifts. Mar. Ecol. Prog. Ser. 599, 1-17 (2018).
55. Vergés, A. et al. The tropicalization of temperate marine ecosystems: climate-mediated changes in herbivory and community phase shifts. Proc. R. Soc. B Biol. Sci. 281, 20140846 (2014).

56. Bulleri, F., Bruno, J. F., Silliman, B. R. \& Stachowicz, J. J. Facilitation and the niche: implications for coexistence, range shifts and ecosystem functioning. Funct. Ecol. 30, 70-78 (2016).

57. Smith, S. M., Fox, R. J., Booth, D. J. \& Donelson, J. M. 'Stick with your kind, or hang with locals?' Implications of shoaling strategy for tropical reef fish on a range-expansion frontline. Glob. Change Biol. 24, 1663-1672 (2018).

58. Kingsbury, K. M., Gillanders, B. M., Booth, D. J., Coni, E. O. C. \& Nagelkerken, I. Range-extending coral reef fishes trade-off growth for maintenance of body condition in cooler waters. Sci. Total Environ. 703, 134598 (2019)

59. Kingsbury, K. M., Gillanders, B. M., Booth, D. J. \& Nagelkerken, I. Trophic niche segregation allows range-extending coral reef fishes to co-exist with temperate species under climate change. Glob. Change Biol. 26, 721-733 (2020).

60. Foo, S. A., Dworjanyn, S. A., Poore, A. G. B. \& Byrne, M. Adaptive capacity of the habitat modifying sea urchin Centrostephanus rodgersii to ocean warming and ocean acidification: performance of early embryos. PLoS ONE 7, e42497 (2012)

61. Kelly, M. W., Padilla-Gamino, J. \& Hofmann, G. E. Natural variation and the capacity to adapt to ocean acidification in the keystone sea urchin Strongylocentrus purpuratus. Glob. Change Biol. 19, 2536-2546 (2013).

62. Uthicke, S. et al. Little evidence of adaptation potential to ocean acidification at a $\mathrm{CO}_{2}$ vent. Ecol. Evol. 9, 10004-10016 (2019).

63. Somero, G. N. The physiology of climate change: how potentials for acclimatization and genetic adaptation will determine 'winners' and 'losers'. J. Exp. Biol. 213, 912-920 (2010).

64. Siikayuopio, A. I., Mortesen, A., Dale, T. \& Foss, A. Effects of carbon dioxide exposure on feed intake and gonad growth in green sea urchin, Stringylicentritus droebachiensis. Aquaculture 266, 97-101 (2007).

65. Dworjanyn, S. A. \& Byrne, M. Impacts of ocean acidification on sea urchin growth across the juvenile to mature adult life-stage transition is mitigated by warming. Proc. R. Soc. B Biol. Sco. 285, 20172684 (2018).

66. Miles, H., Widdicombe, S., Spicer, J. I. \& Hall-Spencer, J. Effects of anthropogenic seawater acidification on acid-base balance in the sea urchin Psammechinus miliaris. Mar. Pollut. Bull. 54, 89-96 (2007).

67. Spicer, J. I., Widdicombe, S., Needham, H. R. \& Berge, J. A. Impact of $\mathrm{CO}_{2}$-acidified seawater on the extracellular acid-base balance of the northern sea urchin Strongylocentrotus dröebachiensis. J. Exp. Mar. Biol. Ecol. 407, 19-25 (2011).

68. Uthicke, S. et al. Echinometra sea urchins acclimatized to elevated $p \mathrm{CO}_{2}$ at volcanic vents outperform those under present-day $p \mathrm{CO}_{2}$ conditions. Glob. Change Biol. 22, 2451-2461 (2016).

69. Wernberg, T. et al. Decreasing resilience of kelp beds along a latitudinal temperature gradient: potential implications for a warmer future. Ecol. Lett. 13, 685-694 (2010).

70. Simonson, E. J., Metaxas, A. \& Scheibling, R. E. Kelp in hot water: effects of warming seawater temperature on kelp quality as a food source and settlement substrate. Mar. Ecol. Prog. Ser. 537, 105-119 (2015).

71. Ross, P. M., Parker, L. \& Byrne, M. Transgenerational responses of molluscs and echinoderms to changing ocean conditions. ICES J. Mar. Sci. 73, 537-549 (2016).

72. Wong, J. M., Johnson, K. M., Kelly, M. W. \& Hofmann, G. E. Transcriptomics reveals transgenerational effects in purple sea urchin embryos: adult acclimation to upwelling conditions alters the response of their progeny to differential pCO ${ }_{2}$ levels. Mol. Ecol. 27, 1120-1137 (2018)

73. Clark, M. S. et al. Molecular mechanisms underpinning transgenerational plasticity in the green sea urchin Psammechinus miliaris. Sci. Rep. 9, 952 (2019)

74. Ghedini, G., Russell, B. D. \& Connell, S. D. Trophic compensation reinforces resistance: herbivory absorbs the increasing effects of multiple disturbances. Ecol. Lett. 18, 182-187 (2015).

75. Munday, P. L., Rummer, J. L. \& Baumann, H. Adaptation and evolutionary responses to high $\mathrm{CO}_{2}$. Fish. Physiol. 37, 369-395 (2019).

76. Miller, G. M., Watson, S. A., Donelson, J. M., McCormick, M. I. \& Munday, P. L. Parental environment mediates impacts of increased carbon dioxide on a coral reef fish. Nat. Clim. Change 2, 858-861 (2012).

77. Allan, B. J. M., Miller, G. M., McCormick, M. I., Domenici, P. \& Munday, P. L. Parental effects improve escape performance of juvenile reef fish in a high- $\mathrm{CO}_{2}$ world. Proc. R. Soc. B Biol. Sco. 281, 20132179 (2014).

78. Welch, M., Watson, S., Welsh, J. Q., McCormick, M. I. \& Munday, P. L. Effect of elevated $\mathrm{CO}_{2}$ on fish behaviour undiminished by transgenerational acclimation. Nat. Clim. Change 4, 1086-1089 (2014).

79. Rummer, J. L. \& Munday, P. L. Climate change and the evolution of reef fishes: past and future. Fish. Fish. (Oxf.) 18, 22-39 (2017).

Publisher's note Springer Nature remains neutral with regard to jurisdictional claims in published maps and institutional affiliations.

(C) The Author(s), under exclusive licence to Springer Nature Limited 2021 


\section{Methods}

Study areas. We combined observations from two subtidal volcanic $\mathrm{CO}_{2}$ vents (New Zealand) and three tropicalization hotspots (south-eastern Australia) (Extended Data Fig. 2). We used these areas as an early warning system to assess the combined consequences of ocean acidification and ocean warming at tropicalization hotspots across temperate coastal ecosystems. Three main rocky-reef habitat types were distinguished ${ }^{80}:$ kelp forests (dominated by Ecklonia radiata), turf-forming algae $\left(<10 \mathrm{~cm}\right.$ in height $\left.{ }^{13}\right)$ and sea urchin barrens (dominated by crustose coralline algae). These barrens are created by the native temperate species (E. chloroticus) and warm-adapted sea urchin C. rodgersii. C. rodgersii creates widespread barren habitat across $\sim 50 \%$ of the shallow reefs in south-eastern Australia, which amounts to several thousand hectares ${ }^{80}$. This species has been largely restricted to the coast of New South Wales, including Sydney, but from $\sim 50$ years ago the range of this species has extended southwards to northern Tasmania ${ }^{9}$ and northern New Zealand ${ }^{81}$.

Although the two stressors were separately evaluated, in areas with distinct environmental features, the two studied regions can be compared because: (1) both are located in shallow temperate rocky-reef ecosystems; (2) they have similar bathymetric zones (shallow reefs ranging from $~ 1-6 \mathrm{~m}$ ); (3) the major benthic components and vegetation are similar (as described above); and (4) the two key ecosystem engineers (sea urchins) occur in both regions. Such similarities indicate that these systems might be used to draw meaningful conclusions at the leading edges of species distributions about the synergistic effect of ocean warming and acidification on the tropicalization of temperate systems.

Natural $\mathrm{CO}_{2}$ vents. Volcanic $\mathrm{CO}_{2}$ vents are naturally enriched in $\mathrm{CO}_{2}$ where the levels of ocean $\mathrm{pH}$ correspond to predicted future levels of ocean acidification, enabling investigation of the prolonged effect of future $\mathrm{CO}_{2}$ concentrations on marine communities in situ ${ }^{40,82}$. The vents studied ( $\sim 6-8 \mathrm{~m}$ depth) were located on the north-eastern coast of an active volcanic island (Bay of Plenty, White Island, New Zealand; $37^{\circ} 31.013^{\prime} \mathrm{S}, 177^{\circ} 11.649^{\prime} \mathrm{E}$ ) where $\mathrm{CO}_{2}$ bubbles are released from the rocky-reef substrate in a total area of $\sim 580 \mathrm{~m}^{2}$. A total of four sites were sampled: two adjacent control areas located approximately $25 \mathrm{~m}$ from the vents, with $\mathrm{pH}$ levels similar to normal conditions (means across years: 8.05-8.08); and two sites with locally reduced seawater $\mathrm{pH}$ (means across years: $7.82-7.88$ ), with values close to RCP projections of 4.5 and 6.0 for the year $2100^{35}$. The southern vent had $\mathrm{pH}$ values that reflected an approximate RCP 4.5 scenario with a reduction of $0.19 \mathrm{pH}$ units compared with the control site, while the northern vent showed a pH reduction of 0.24 units, which is close to an RCP 6.0 scenario (Supplementary Table 1). The $\mathrm{pH}$ levels at the vents were relatively stable over time and were not confounded by other physico-chemical variables (Supplementary Table 2). These $\mathrm{pH}$ reductions represent moderate end-of-century predictions rather than a more extreme RCP 8.5 scenario reflective of no greenhouse gas mitigation measures ${ }^{83}$.

At $\mathrm{CO}_{2}$ vent sites, the benthic community is primarily composed of turfs where $\mathrm{CO}_{2}$ concentrations are elevated, whereas outside this $\mathrm{CO}_{2}$ influence, kelp and barrens form mosaics with turfs ${ }^{13}$. The fish community is composed of a few roving species (which are unlikely to be continuously exposed to the low $\mathrm{pH}$ levels at the vents due to their high mobility) and a large community (comprising $>90 \%$ of the total fish density) of territorial and site-attached species composed mainly of triplefins and blennies. At the $\mathrm{CO}_{2}$ vents, we defined fish assemblage as species with a well-defined and small home range and low mobility that were within the $\mathrm{CO}_{2}$ plume and were directly affected by elevated $\mathrm{CO}_{2}$. By using only species that matched these criteria (low mobility and small home range), such as triplefins and blennies, we were able to draw stronger conclusions about the effects of habitat modification triggered by $\mathrm{CO}_{2}$ on a fish community. Previous studies showed that seawater temperature does not differ among the four sites and the $\mathrm{pH}$ values show only small variation at any given site over the day ${ }^{11,13}$.

Tropicalization hotspots. Over the past two decades, Sydney's coastal areas (New South Wales, Australia) have experienced arrivals of an increasing diversity and density of vagrant tropical fishes that annually recruit there throughout the summer $(\sim 100 \text { species })^{38}$. There has been a gradual increase in the abundance of overwintering survivors due to increasing coastal seawater temperatures ${ }^{84}$. All of these factors, in combination with the gradual strengthening of warmer currents (for example, the East Australia Current) moving down from tropical regions to high latitudes ${ }^{85,86}$, make the Sydney coast a tropicalization hotspot ${ }^{4,87}$. We selected the same sites where vagrant tropical fish assemblages have been regularly monitored for nearly 18 years (Sydney's Cabbage Tree Bay, Fairy Bower and Little Manly). These reefs are dominated by a mosaic of the three main types of habitat (kelp, turf and barrens) in addition to patches of oyster reefs, which were also used in this study because of their importance as a habitat provider for many organisms ${ }^{88}$ including some tropical fishes that were observed using this habitat as a refuge. Oyster reefs were once a common habitat of temperate coastal waters in New South Wales, but after severe overharvesting only small patches persist in the intertidal zone $e^{89}$

Study design. Fish density and diversity. The abundance and diversity of local (temperate) and vagrant (tropical) fishes were estimated in south-eastern Australia
(2017-2018), and those of local species in New Zealand were estimated between February and April in the years 2017 and 2018. Visual surveys estimated the density of fish within sampling units that were randomly distributed among patches of the most common habitats identified for each region (see 'Study areas' above).

The specific method used to quantify fish assemblages was designed to best represent the local assemblage and the size and shape of habitats. At the vents in New Zealand, only some species (for example, triplefins, blennies and scorpionfish) were considered because these species are site attached and the consequences of long-term exposure to elevated $\mathrm{CO}_{2}$ at vents could be properly investigated. The site-attached fish assemblage studied was identified to the species level and visually quantified in a replicate stationary circular census. Due to the small fish body sizes, the counts were made in small cylindrical survey areas of $1 \mathrm{~m}$ diameter. Fishes were counted inside the cylinder for approximately $1 \mathrm{~min}$. This approach produced the best density estimates for small fishes $(\leq 10 \mathrm{~cm})$ (methodology adapted from Minte-Vera et al. ${ }^{90}$ ). Individual fish body size was also estimated between two categories ( $<5$ and $>10 \mathrm{~cm}$ total length). At each of the two control sites, a total of $\sim 15$ quadrats were surveyed per habitat (kelp, turf and barrens). At the vents, the benthic cover was dominated by turf habitat; therefore, 27 quadrats were surveyed for this habitat at the vent sites (11 at the southern vent and 16 at the northern vent).

In the Sydney area, belt transects were used to quantify the temperate and tropical fish assemblages in each main benthic habitat type identified in this region. About 15-30 transects were surveyed per habitat (kelp, turf, barren and oyster banks). The method consisted of a diver swimming along a transect of $10 \mathrm{~m}$ length, identifying and counting all fishes, including their respective body length (size categories of $<5,5-10,10-20,20-30$ and $>30 \mathrm{~cm}$ total length), within $2 \mathrm{~m}$ of each side of the transect tape $\left(40 \mathrm{~m}^{2}\right.$ area per transect). All benthic and pelagic fish species were included. First, the larger fishes were counted and then, for the same transect, an intensive search for small and cryptic species was performed between and underneath kelp leaves, rocks and inside crevices (methodology adapted from Fulton et al..$^{11}$ ). The difference in census area and shape between the two regions (Australia versus New Zealand) corresponds to the length and shape of the habitats. Larger census areas in Sydney were used because of the larger and longer patches of habitats compared with those in New Zealand.

For both study regions, differences in the fish assemblage among habitats were evaluated at the individual species and functional levels. Fishes were split into major functional groups according to their diet and feeding habits: (1) planktivores; (2) omnivores; (3) invertivores; (4) herbivores; and (5) carnivores (fish and invertebrate feeders). Additionally, because the herbivorous fish community is not a homogeneous group, we subdivided them into: (6) solely epilithic algae matrix feeders (roving grazing herbivores, territorial grazing herbivores and herbivorous detritivores); (7) solely browsing herbivores (macroalgae feeders); (8) combined browsing and grazing herbivores (epilithic algae matrix and macroalgae feeders); and (9) kelp feeders. These categories follow Choat and Clements ${ }^{92}$, Clements and Choat ${ }^{93}$, Ceccarelli ${ }^{94}$ and Zarco-Perello et al. ${ }^{95}$. All diet information and functional characteristics were collected from FishBase ${ }^{96}$. As the benthic fish species in New Zealand were all part of the same functional group (that is, invertivores (following FishBase)), functional group analysis was not performed for the New Zealand study area.

$\mathrm{CO}_{2}$ effects on sea urchin populations. In New Zealand, sea urchin densities were quantified inside circular quadrats of $2 \mathrm{~m}$ diameter at the same patches of habitats where the fishes were surveyed. A total of 15 circular quadrats were performed in turf habitats at the vents and each of the three habitats at control locations. A maximum of ten sea urchins within each habitat were randomly selected and their body sizes (longest diameter) were measured using callipers. In total, the body sizes of $\sim 400$ native sea urchins and 30 warm-adapted sea urchins (due to their lower abundance compared with the natives) were measured. Finally, after each survey, we measured the largest and smallest dimensions of 15 patches of barrens at control sites to calculate the area $\left(\mathrm{m}^{2}\right)$ of each barren and correlate sea urchin abundances with barren size. At the end of each survey, seawater samples were collected directly above the substrate of each circular transect to measure seawater pH. A diagram summarizing the methodology is shown in Supplementary Fig. 6.

Statistical analysis. A canonical analysis of principal coordinates (CAP) was used to evaluate the relationship between habitat type and taxonomic and functional fish assemblages. The decision to use a constrained analysis (CAP) over an unconstrained analysis was because constrained data are normally considered the most appropriate for multivariate analysis, especially when there is an a priori assumption of how explanatory variables (in this case, habitats) determine response variable values (in this case, species abundance) measured in the same set of objects (for example, samples or sites). In addition, constrained ordination analysis uncovers patterns that are masked in unconstrained multivariate analyses (for example, nMDS ordination), allowing us to better visualize specific differences between habitat types ${ }^{97,98}$

As the tropical and temperate fishes do not share the same taxonomic composition, comparisons between these two different communities were performed based on species functionality ${ }^{99}$. Hence, comparing the function exhibited by vagrant tropical and temperate species might reveal their potential 
to compete and/or share the same resources. To reduce the contribution of disproportionately abundant species to the analysis, the data were square-root transformed. Dissimilarities in the taxonomic and functional abundance of fish assemblages (tropical, temperate and $\mathrm{CO}_{2}$ vent fish assemblages) were calculated using one-way ANOSIM and ANOVAs were then used to test for univariate differences in the species richness, density and biomass of fish between the factors of origin (tropical versus temperate) and habitat (kelp dominated versus barren dominated versus turf dominated versus oyster dominated versus $\mathrm{CO}_{2}$ vents), using habitat as a fixed factor. The biomass of each community was obtained by converting fish counts to biomass using length-weight relationships from FishBase $^{96}$. Estimates were calculated by multiplying the weight from the midpoint of each size category by the number of fish per size category and them summing the size categories ${ }^{100}$. Similarity percentage analysis was used to evaluate which species and functional groups mostly contributed to dissimilarities among habitat types. Ordination and similarity analyses were performed using PRIMER 6 software. Student-Newman-Keuls multiple comparisons of means were performed as post-hoc tests for all ANOVAs, and pairwise comparisons of the mean were used in the ANOSIMs ${ }^{101}$

To test the relationships between sea urchin density and $\mathrm{pH}$, barren size and $\mathrm{pH}$ and urchin density and urchin body size, simple linear regression analyses

12 were used. Finally, differences in sea urchin size across habitats were tested using a one-way ANOVA. Regression and ANOVAs were conducted using R software version 3.4.1.

Ethics. All experiments were performed under animal ethics approval numbers S-2015-222A and S-2017-002, and according to the University's animal ethics

Q13 guidelines.

Reporting Summary. Further information on research design is available in the Nature Research Reporting Summary linked to this article.

\section{Data availability}

The data that support the findings of this study are available from the

Q15 corresponding author upon request.

\section{References}

80. Brinkman, T. J. \& Smith, A. M. E. Effects of climate change on crustose coralline algae at a temperate vent site, White Island, New Zealand. Mar. Freshw. Res. 66, 360-370 (2015).

81. Hughes, T. P. et al. Coral reefs in the Anthropocene. Nature 596, 82-90 (2017).

82. Booth, D. J., Beretta, G. A., Brown, L. \& Figueira, W. F. Predicting success of range-expanding coral reef fish in temperate habitats using fish in temperature-abundance relationships. Front. Mar. Sci. 5, 31 (2018).

83. Ridgeway, K. R. Long-term trend and decadal variability of the southward penetration of the East Australian Current. Geophys. Res. Lett. 34, L13613 (2007).

84. Hobday, A. J. \& Pecl, G. T. Identification of global marine hotspots: sentinels for change and vanguards for adaptation action. Rev. Fish Biol. Fish. 24, 415-425 (2013).

85. Figueira, W. F. \& Booth, D. J. Increasing ocean temperatures allow tropical fishes to survive overwinter in temperate waters. Glob. Change Biol. 16, 506-516 (2010).

86. McLeod, I. et al. Habitat value of Sydney rock oyster (Saccostrea glomerata) reefs on soft sediments. Mar. Freshw. Res. 71, 771-781 (2019).

87. Gillies, C. L. et al. Australian shellfish ecosystems: past distribution, current status and future direction. PLoS ONE 13, e0190914 (2018).

88. Minte-Vera, C. V., Moura, R. L. \& Francini-Filho, R. B. Nested sampling: an improved visual-census technique for studying reef fish assemblages. Mar. Ecol. Prog. Ser. 367, 283-293 (2008).

89. Fulton, C. J., Noble, M. N., Radford, B., Gallen, C. \& Harasti, D. Microhabitat selectivity underpins regional indicators of fish abundance and replenishment. Ecol. Indic. 70, 222-231 (2016).

90. Choat, J. H. \& Clements, K. D. Diet in Odacid and Aplodactylid fishes from Australia and New Zealand. Aust. J. Mar. Freshw. Res. 43, 1451-1459 (1992).
91. Clements, K. D. \& Choat, J. H. Comparison of herbivory in the closely-related marine fish genera Girella and Kyphosus. Mar. Biol. 127, 579-586 (1997).

92. Ceccarelli, D. M. Modification of benthic communities by territorial damselfish: a multi-species comparison. Coral Reefs 26, 853-866 (2007).

93. Zarco-Perello, S., Wemberg, T., Langlois, T. J. \& Vanderklift, M. A. Tropicalization strengthens consumer pressure on habitat-forming seaweeds. Sci. Rep. 7, 820 (2017).

94. Froese, R. \& Pauly, D. FishBase (2016); http://www.fishbase.org

95. Anderson, M. J. \& Willis, T. J. Canonical analysis of principal coordinates: a useful method of constrained ordination for ecology. Ecology 84, 511-525 (2003)

96. Paliy, O. \& Shankar, V. Application of multivariate statistical techniques in microbial ecology. Mol. Ecol. 25, 1032-1057 (2016).

97. Anderson, M. J. A new method for non-parametric multivariate analysis of variance. Austral Ecol. 26, 32-46 (2001).

98. Hemingson, C. R. \& Bellwood, D. R. Biogeographic patterns in major marine realms: function not taxonomy unites fish assemblages in reef, seagrass and mangrove systems. Ecography 41, 174-182 (2018).

99. Wernberg, T. et al. An extreme climatic event alters marine ecosystem structure in a global biodiversity hotspot.Nat. Clim. Change 3, 78-82 (2013).

100. Johnson, C. R. et al. Climate change cascades: shifts in oceanography, species' ranges and subtidal marinecommunity dynamics in eastern Tasmania.J. Exp. Mar. Biol. Ecol. 400, 17-32 (2011).

101. Scheffer, M. Critical Transitions in Nature and Society (Princeton Univ. Press, 2009).

102. McClanahan, T. R. \& Kaunda-Arara, B. Fishery recovery in a coral-reef marine park and its effect on the adjacent fishery. Conserv. Biol. 10, 1187-1199 (1996).

103. Jax, K. 'Threshold, tipping points and limits' in OpenNESS Ecosystem Services Reference Book (eds Potschin, M. \& Jax, K.) (2016).

104. Connell, S. D. \& Irving, A. D. Integrating ecology with biogeography using landscape characteristics: a case study of subtidal habitat across continental Australia. J. Biogeogr. 35, 1608-1621 (2008).

105. Pecorino, D., Lamare, M. D. \& Barker, M. F. Growth, morphometrics and size structure of the Diamatidae sea urchin Centrostephanus rodgersii in northern New Zealand. Mar. Freshw. Res. 63, 624-634 (2012).

\section{Acknowledgements}

We thank K. Kingsbury, M. Sasaki and M. Krutz for logistic support in the field. This project was funded by Australian Research Council (ARC) Discovery Project DP170101722 to I.N. and D.J.B. Additional financial support was provided by an ARC Future Fellowship to I.N. (grant number FT120100183), an ARC Discovery Project to S.D.C. (grant number DP150104263) and a grant from the Environment Institute (University of Adelaide).

\section{Author contributions}

E.C., I.N., D.J.B. and S.D.C. conceived of and designed the study. E.C. and C.F collected the data. E.C. analysed the data. E.C., I.N., D.J.B. and S.D.C. wrote the article.

\section{Competing interests}

The authors declare no competing interests.

\section{Additional information}

Extended data is available for this paper at https://doi.org/10.1038/s41558-020-00980-w.

Supplementary information The online version contains supplementary material available at https://doi.org/10.1038/s41558-020-00980-w.

Correspondence and requests for materials should be addressed to I.N.

Peer review information Nature Climate Change thanks Cristina Linares and the other, anonymous, reviewer(s) for their contribution to the peer review of this work.

Reprints and permissions information is available at www.nature.com/reprints. 
a)

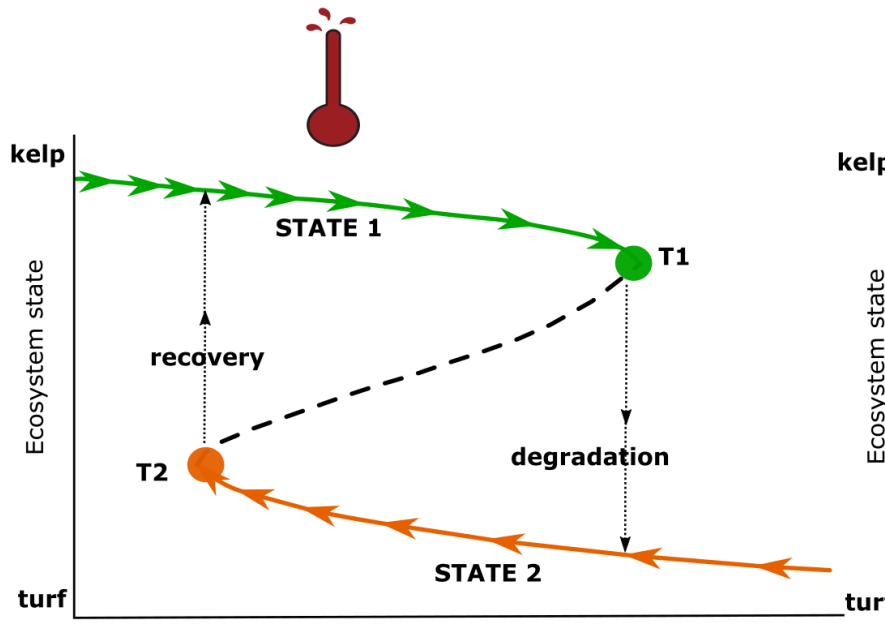

stressor intensity

c)
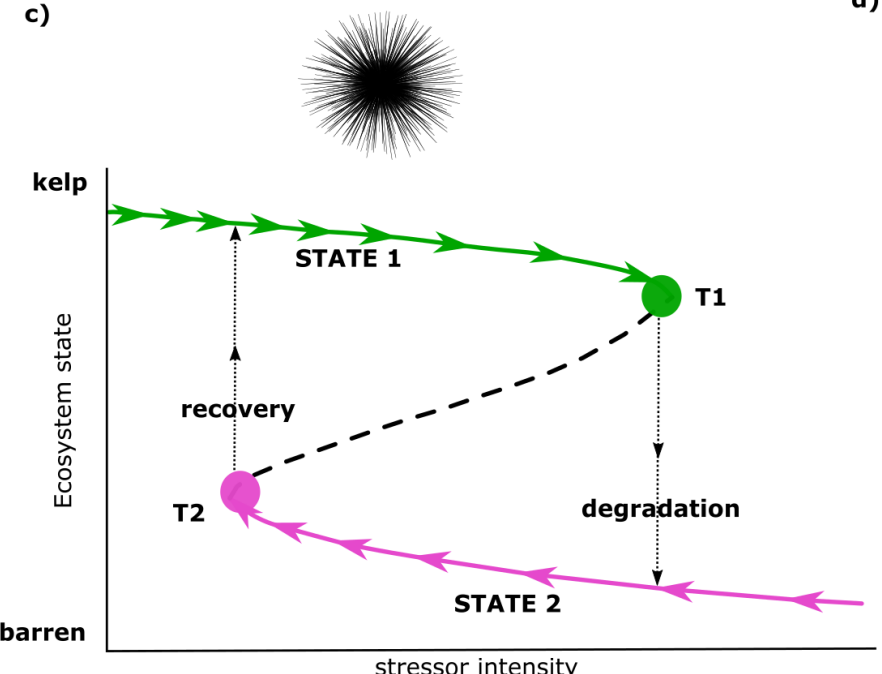

b)

d)
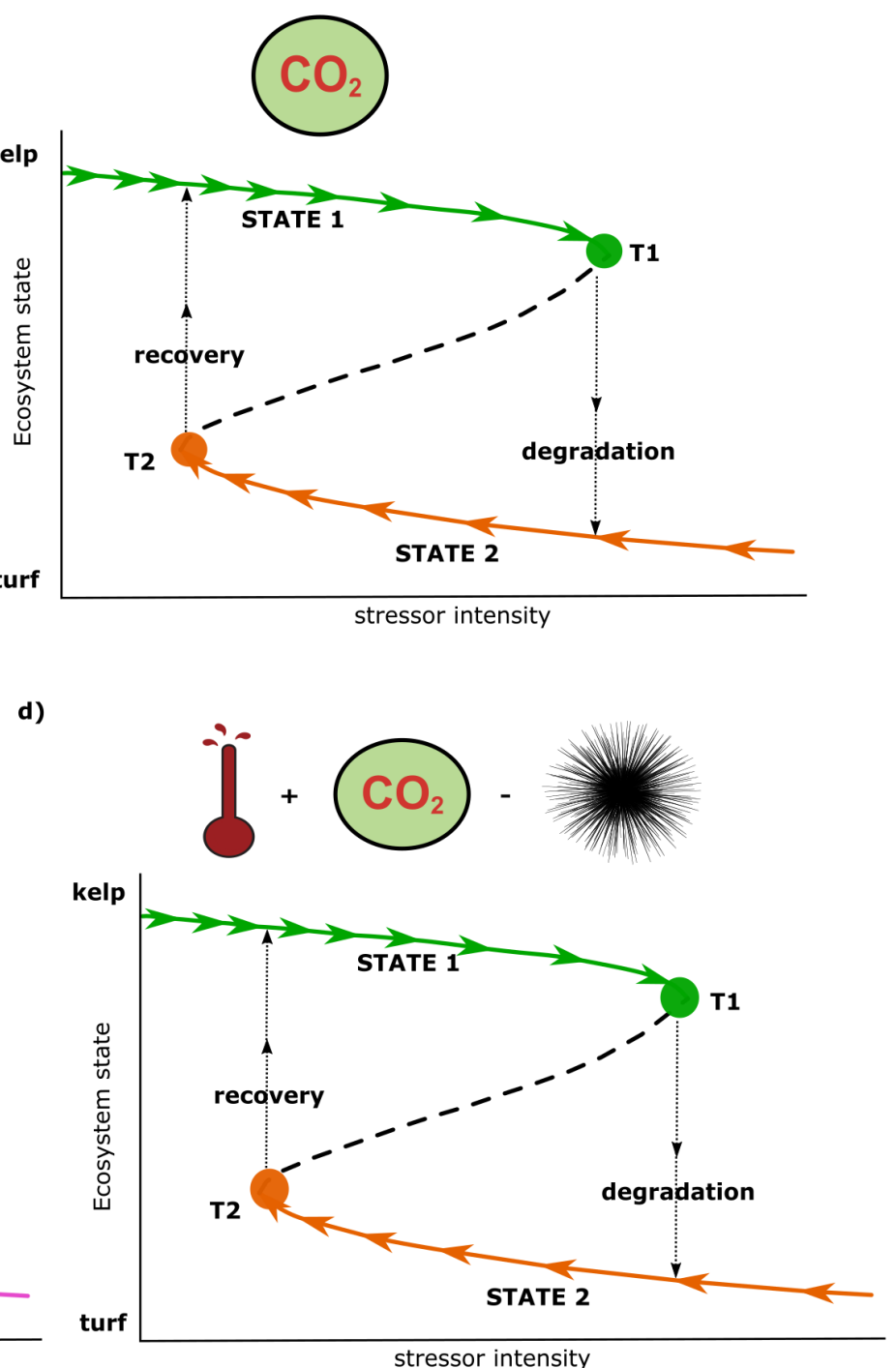

Extended Data Fig. 1 | Conceptual models of hysteresis under different climate change stressors. Regime shifts from kelp forests (green solid lines) to alternative turf and barren-dominated states (orange and pink solid lines) and the occurrence of hysteresis under different climate change scenarios: (a) ocean warming ${ }^{12,102},(\mathbf{b})$ ocean acidification ${ }^{16},(\mathbf{c})$ urchin overgrazing ${ }^{3,103}$, and (d) all three stressors combined (present study). When the stressors are strong enough, and ecosystem state 1 passes beyond the tipping point ( $\mathrm{T} 1$ ), a discontinuous critical transition occurs from an unstable equilibrium (dashed line) to the alternative stable state 2 (degradation) (downward black arrow). However, if stressor levels are then reduced, a hysteresis occurs because the opposing forces fail to push the ecosystem to return to its original state. The recovery to state 1 is only possible if the magnitude of the stressors is reduced to a much lower level (T2) (upward black arrows) than that of the tipping point during the degradation. Adapted from Scheffer ${ }^{104}$ and Jax ${ }^{105}$. 


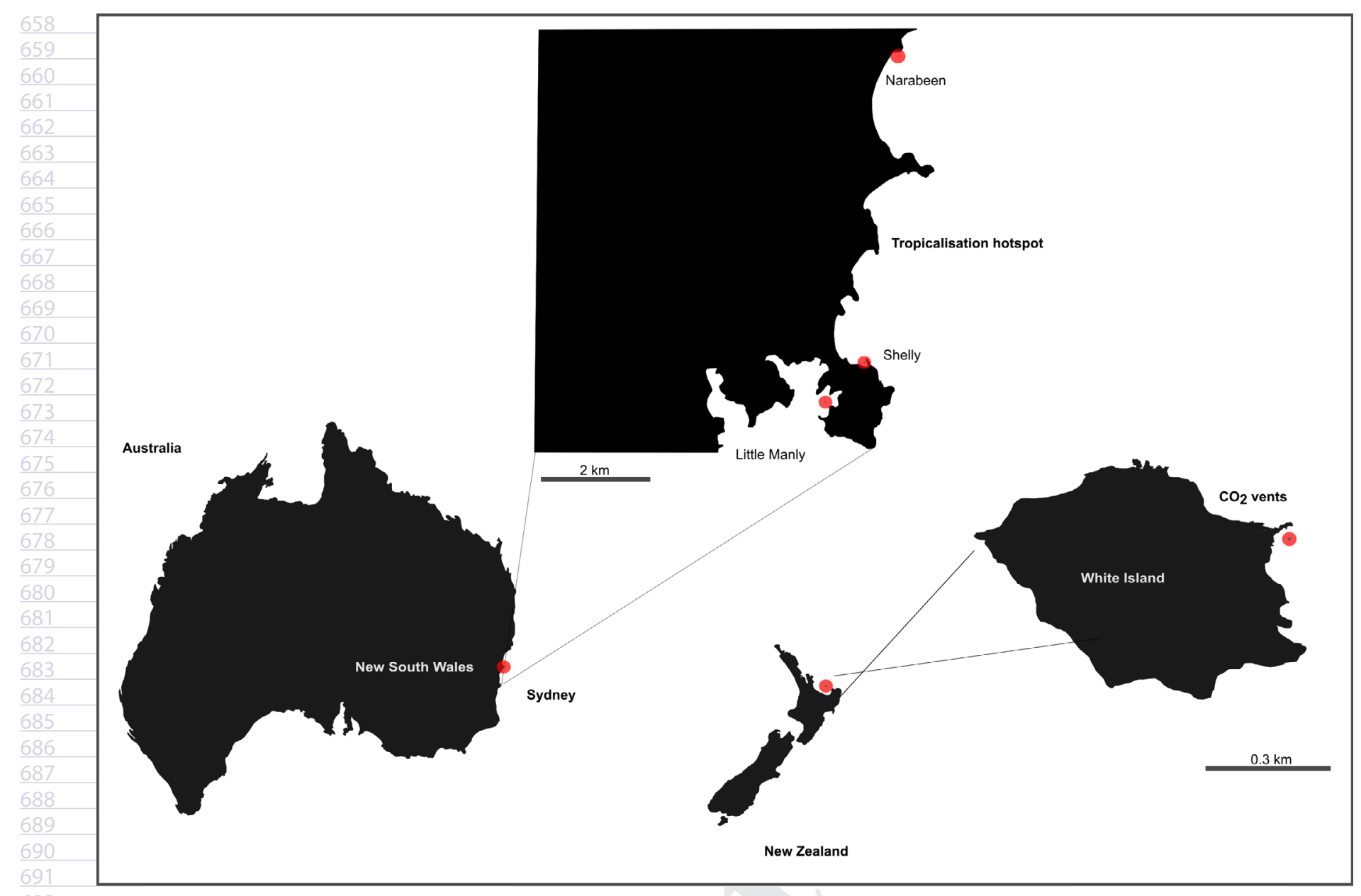

Extended Data Fig. 2 | Tropicalisation hotspot and $\mathrm{CO}_{2}$ vent study areas. Map showing the three tropicalisation hotspots in Sydney (Australia) where tropical and temperate fish communities were surveyed, and the $\mathrm{CO}_{2}$ vents at White Island (New Zealand) where the effects of elevated $\mathrm{CO}_{2}$ on fish communities and sea-urchins were investigated. 


\section{QUERY FORM}

\section{Nature Climate Change}

\begin{tabular}{|l|c|}
\hline Manuscript ID & [Art. Id: 980] \\
\hline Author & Ericka Coni \\
\hline
\end{tabular}

\section{AUTHOR:}

The following queries have arisen during the editing of your manuscript. Please answer by making the requisite corrections directly in the e.proofing tool rather than marking them up on the PDF. This will ensure that your corrections are incorporated accurately and that your paper is published as quickly as possible.

\begin{tabular}{|c|c|}
\hline Query No. & Nature of Query \\
\hline Q1: & $\begin{array}{l}\text { Please check your article carefully, coordinate with any co-authors and enter all final edits clearly in the eproof, } \\
\text { remembering to save frequently. Once corrections are submitted, we cannot routinely make further changes to } \\
\text { the article. }\end{array}$ \\
\hline Q2: & $\begin{array}{l}\text { Note that the eproof should be amended in only one browser window at any one time; otherwise changes will } \\
\text { be overwritten. }\end{array}$ \\
\hline Q3: & $\begin{array}{l}\text { Author surnames have been highlighted. Please check these carefully and adjust if the first name or surname } \\
\text { is marked up incorrectly. Note that changes here will affect indexing of your article in public repositories such } \\
\text { as PubMed. Also, carefully check the spelling and numbering of all author names and affiliations, and the cor- } \\
\text { responding email address(es). }\end{array}$ \\
\hline Q4: & $\begin{array}{l}\text { You cannot alter accepted Supplementary Information files except for critical changes to scientific content. If } \\
\text { you do resupply any files, please also provide a brief (but complete) list of changes. If these are not considered } \\
\text { scientific changes, any altered Supplementary files will not be used, only the originally accepted version will be } \\
\text { published. }\end{array}$ \\
\hline Q5: & $\begin{array}{l}\text { If applicable, please ensure that any accession codes and datasets whose DOIs or other identifiers are mentioned } \\
\text { in the paper are scheduled for public release as soon as possible, we recommend within a few days of submitting } \\
\text { your proof, and update the database record with publication details from this article once available. }\end{array}$ \\
\hline Q6: & $\begin{array}{l}\text { Please note that references } 80-83 \text { from your original main text section have been renumbered as references } 102- \\
105 \text {, which are cited in the caption to Extended Data Fig. } 1 \text {. Please check this is correct. }\end{array}$ \\
\hline Q7: & $\begin{array}{l}\text { Please check that the edits to the Fig. } 2 \text { caption retain the intended meaning. Note that panels } h-j \text { have been } \\
\text { relabelled g-i since there was no panel g in the original figure. The text citation has been amended to match. }\end{array}$ \\
\hline Q8: & $\begin{array}{l}\text { In the main text and Fig. } 2 \text { caption, you refer to species 'density' in relation to Fig. } 2 \text { panels b, e and h. However, } \\
\text { the y axis label in the figure says 'diversity'. Please clarify which is correct and ensure the term is consistent } \\
\text { throughout. }\end{array}$ \\
\hline Q9: & Please expand 'ind' in the y axis label in Figs. $2 b$ and $4 a, b$. \\
\hline Q10: & $\begin{array}{l}\text { Please check that the edits to the sentence 'Finally, after each survey, we measured the largest...' retain the in- } \\
\text { tended meaning. }\end{array}$ \\
\hline Q11: & $\begin{array}{l}\text { In the sentence 'In addition, constrained ordination analysis uncovers patterns that are masked...' please expand } \\
\text { 'nMDS'. }\end{array}$ \\
\hline
\end{tabular}




\section{QUERY FORM}

\begin{tabular}{|l|c|}
\hline \multicolumn{2}{|c|}{ Nature Climate Change } \\
\hline Manuscript ID & [Art. Id: 980] \\
\hline Author & Ericka Coni \\
\hline
\end{tabular}

\section{AUTHOR:}

The following queries have arisen during the editing of your manuscript. Please answer by making the requisite corrections directly in the e.proofing tool rather than marking them up on the PDF. This will ensure that your corrections are incorporated accurately and that your paper is published as quickly as possible.

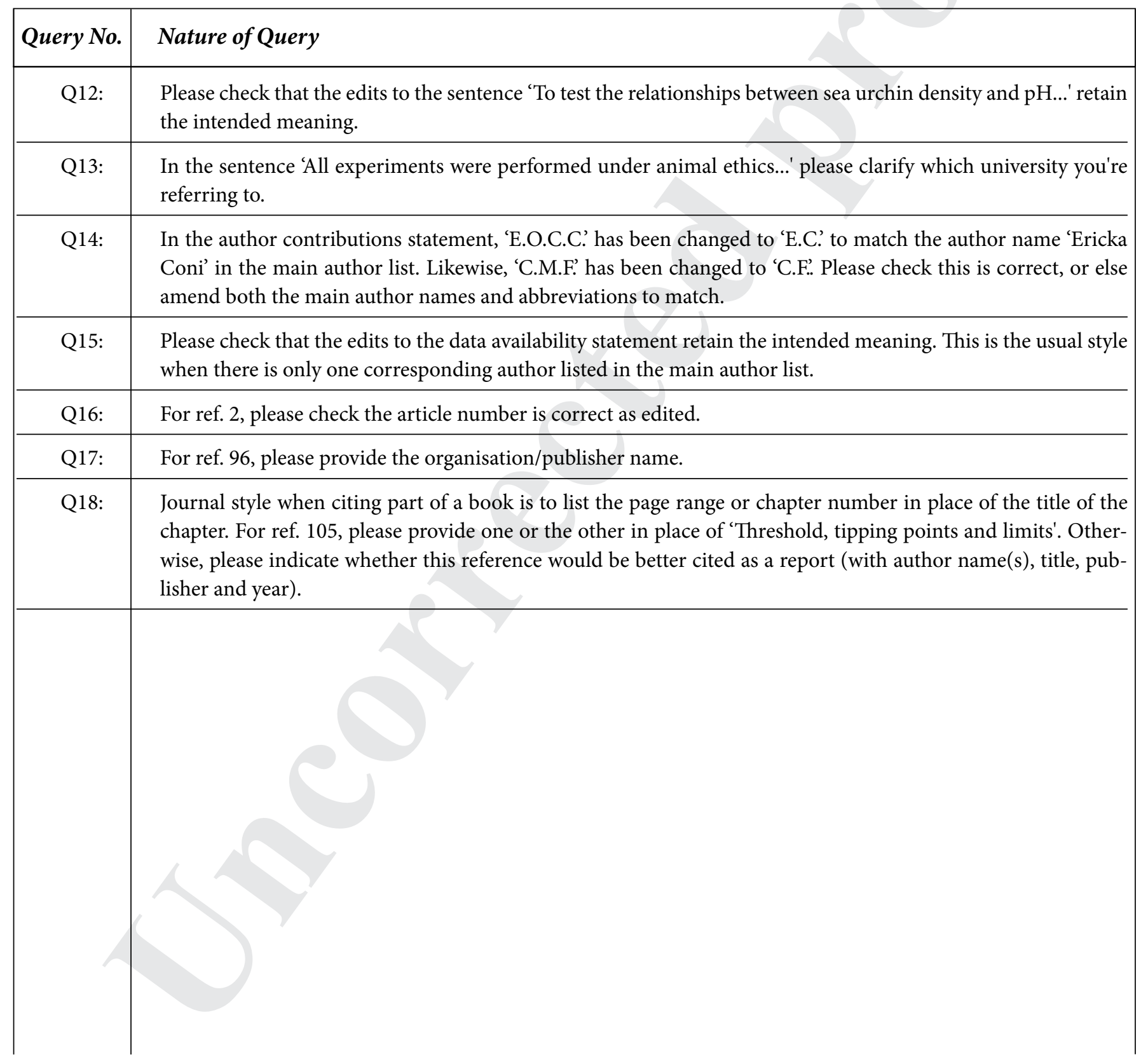




\section{natureresearch}

Corresponding author(s): Ivan Nagelkerken

Last updated by author(s): 11-11-2020

\section{Reporting Summary}

Nature Research wishes to improve the reproducibility of the work that we publish. This form provides structure for consistency and transparency in reporting. For further information on Nature Research policies, see Authors \& Referees and the Editorial Policy Checklist.

\section{Statistics}

For all statistical analyses, confirm that the following items are present in the figure legend, table legend, main text, or Methods section.

$\mathrm{n} / \mathrm{a}$ Confirmed

Х The exact sample size $(n)$ for each experimental group/condition, given as a discrete number and unit of measurement

$\square$ \ A statement on whether measurements were taken from distinct samples or whether the same sample was measured repeatedly

$\triangle \square$ The statistical test(s) used AND whether they are one- or two-sided

Only common tests should be described solely by name; describe more complex techniques in the Methods section.

$\bigotimes \square$ A description of all covariates tested

$\square \bigotimes$ A description of any assumptions or corrections, such as tests of normality and adjustment for multiple comparisons

$\checkmark$ A full description of the statistical parameters including central tendency (e.g. means) or other basic estimates (e.g. regression coefficient)

AND variation (e.g. standard deviation) or associated estimates of uncertainty (e.g. confidence intervals)

For null hypothesis testing, the test statistic (e.g. $F, t, r$ ) with confidence intervals, effect sizes, degrees of freedom and $P$ value noted

Give P values as exact values whenever suitable.

$\bigotimes \square$ For Bayesian analysis, information on the choice of priors and Markov chain Monte Carlo settings

Х $\square$ For hierarchical and complex designs, identification of the appropriate level for tests and full reporting of outcomes

$\triangle \square$ Estimates of effect sizes (e.g. Cohen's $d$, Pearson's $r$ ), indicating how they were calculated

Our web collection on statistics for biologists contains articles on many of the points above.

\section{Software and code}

\section{Policy information about availability of computer code}

\section{Data collection n/a}

Data analysis All analyses were performed using R software version 3.4.1 (package agricolae) and PRIMER version 6 software.

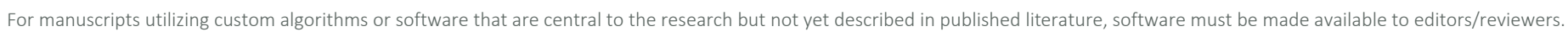
We strongly encourage code deposition in a community repository (e.g. GitHub). See the Nature Research guidelines for submitting code \& software for further information.

\section{Data}

Policy information about availability of data

All manuscripts must include a data availability statement. This statement should provide the following information, where applicable:

- Accession codes, unique identifiers, or web links for publicly available datasets

- A list of figures that have associated raw data

- A description of any restrictions on data availability

The data that support the findings of this study are available from the corresponding author upon reasonable request.

\section{Field-specific reporting}

Please select the one below that is the best fit for your research. If you are not sure, read the appropriate sections before making your selection.

$\bigotimes$ Life sciences $\quad \square$ Behavioural \& social sciences $\square$ Ecological, evolutionary \& environmental sciences

For a reference copy of the document with all sections, see nature.com/documents/nr-reporting-summary-flat.pdf 
All studies must disclose on these points even when the disclosure is negative.

Sample size The field sampling was conducted during the summers of 2017 and 2018. The data collection in 2018 was primarily to fill data gaps (i.e. number of replicates) that were found after performing some preliminary statistical analyses using the 2017 data. Based on the preliminary statistical analyses, literature, and previous experiments, we established the minimum number of replicates to ensure adequate statistical power.

Data exclusions No data were excluded from the analysis

Replication All the data were collected through observations in the field. The methodology is described in detail in the manuscript to allow replication of this study.

Randomization The data in the present study were collected through underwater visual surveys to estimate the density of fishes and sea urchins within sampling units that were randomly distributed among patches of the most common habitats (kelp, urchin barren, turf-forming algae) identified for each study region (Sydney and New Zealand).

Blinding Blinding was not relevant in this study because all surveys were performed in situ, based on underwater observations.

\section{Reporting for specific materials, systems and methods}

We require information from authors about some types of materials, experimental systems and methods used in many studies. Here, indicate whether each material, system or method listed is relevant to your study. If you are not sure if a list item applies to your research, read the appropriate section before selecting a response.

\begin{tabular}{|c|c|c|c|}
\hline \multicolumn{2}{|c|}{ Materials \& experimental systems } & \multicolumn{2}{|c|}{ Methods } \\
\hline $\mathrm{n} / \mathrm{a}$ & Involved in the study & $\mathrm{n} / \mathrm{a}$ & Involved in the study \\
\hline 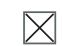 & $\square$ Antibodies & Х & $\square$ ChIP-seq \\
\hline$\bigotimes$ & $\square$ Eukaryotic cell lines & Х & $\square$ Flow cytometry \\
\hline$\bigotimes$ & $\square$ Palaeontology & Х & $\square$ MRI-based neuroimaging \\
\hline$\bigotimes$ & $\square$ Animals and other organisms & & \\
\hline$\bigotimes$ & $\square$ Human research participants & & \\
\hline Х & $\square$ Clinical data & & \\
\hline
\end{tabular}

